\title{
A new analysis workflow for discrimination of nuclear grade graphite using laser-induced breakdown spectroscopy \\ DOI:
}

10.1016/j.jenvrad.2019.01.004

\section{Document Version}

Accepted author manuscript

Link to publication record in Manchester Research Explorer

Citation for published version (APA):

Horsfall, J. P. O., Trivedi, D., Smith, N. T., Martin, P. A., Coffey, P., Tournier, S., Banford, A., Li, L., Whitehead, D., Lang, A., \& Law, G. T. W. (2019). A new analysis workflow for discrimination of nuclear grade graphite using laserinduced breakdown spectroscopy. Journal of Environmental Radioactivity, 199-200, 45-57.

https://doi.org/10.1016/j.jenvrad.2019.01.004

Published in:

Journal of Environmental Radioactivity

\section{Citing this paper}

Please note that where the full-text provided on Manchester Research Explorer is the Author Accepted Manuscript or Proof version this may differ from the final Published version. If citing, it is advised that you check and use the publisher's definitive version.

\section{General rights}

Copyright and moral rights for the publications made accessible in the Research Explorer are retained by the authors and/or other copyright owners and it is a condition of accessing publications that users recognise and abide by the legal requirements associated with these rights.

\section{Takedown policy}

If you believe that this document breaches copyright please refer to the University of Manchester's Takedown Procedures [http://man.ac.uk/04Y6Bo] or contact uml.scholarlycommunications@manchester.ac.uk providing relevant details, so we can investigate your claim.

\section{OPEN ACCESS}




\section{Manuscript Details}

\section{Manuscript number}

Title
JENVRAD_2018_374_R2

A new analysis workflow for discrimination of nuclear grade graphite using laserinduced breakdown spectroscopy

Research Paper

\section{Article type}

Abstract

Stand-off, in-situ, laser induced breakdown spectroscopy (LIBS) offers a rapid, safe, and cost-effective method for discrimination of radioactive waste materials arising during the operation of nuclear plants and from decommissioning activities. Characterisation of waste materials is a critical activity in understanding the nature of the waste, ensuring hazardous material is managed safely and that waste can be segregated for reuse, recycle or sentenced for appropriate disposal. Characterisation of materials, often in hostile environments, requires the ability to remotely differentiate between materials in terms of their chemical composition and radioactivity. This proposition was tested using a case study on nuclear grade graphite. Graphite has been used extensively as a moderator material in many nuclear reactors. Internationally, over 250,000 tons of various nuclear-grade graphite, and graphite-bearing, materials exist and are a major issue for nuclear decommissioning and radioactive waste management, due to the long half-lives of the associated $14 \mathrm{C}$ and $36 \mathrm{Cl}$ isotopes. LIBS offers a method for discrimination of nuclear grade graphites and other carbon and non-carbon-bearing wastes. This paper describes the development of a workflow method, including LIBS measurement analysis, for the discrimination of pre-irradiated nuclear 'Pile Grade A' (PGA) graphite moderator rod and domestic lumpwood charcoal, which act as surrogates for nuclear grade graphite and other carbon-bearing wastes. A new analysis workflow comprising the examination of spectral characteristics, multivariate analysis and molecular isotopic spectroscopy is proposed to enable rapid segregation of graphite from a heterogeneous waste stream. Enhanced characterisation techniques have the potential to significantly reduce the cost of decommissioning large parts of legacy nuclear generation plants.

\section{Keywords}

Taxonomy

Corresponding Author

Order of Authors

Suggested reviewers
LIBS fingerprinting; i-graphite; decommissioning; waste management

Radioactive Waste Process, Radioactive Waste Disposal, Nuclear Decommissioning, Radioactive Waste Management

John Horsfall

John Horsfall, Divyesh Trivedi, Nicholas Smith, Philip Martin, Paul Coffey, Stella Tournier, Anthony Banford, Lin Li, David Whitehead, Adam Lang, Gareth Law

Leon Black, Fabienne Boue-Bigne, Shiv Sharma

\section{Submission Files Included in this PDF}

\section{File Name [File Type]}

Reviewers comments + Author decisions for Charcoal vs Graphite paper v6.docx [Response to Reviewers (without Author Details)]

Highlights.docx [Highlights]

Revised Abstract.docx [Abstract]

Revised Title page.docx [Title Page (with Author Details)]

Manuscript with revisions v6.docx [Manuscript (without Author Details)]

Figures revised v2.docx [Figure]

Tables v2.docx [Table]

Covering Letter.pdf [Supporting File]

Covering letter for the revised manuscript.docx [Supporting File]

To view all the submission files, including those not included in the PDF, click on the manuscript title on your EVISE Homepage, then click 'Download zip file'. 


\section{Reviewers feedback, and authors responses}

\begin{tabular}{|c|c|c|}
\hline Item & Reviewers' feedback & Authors' comments \\
\hline 1. & $\begin{array}{l}\text { 1/ Abstract: good length and content. lines 22-23: however, you cannot really say the } \\
\text { paper is about "...the successful use of LIBS analysis for the discrimination...", as it is not } \\
\text { about the application of LIBS for this segregation measurement itself at this point. No } \\
\text { large numbers of samples were measured, nor blind measurement were performed, etc. } \\
\text { The paper is rather about the "development of a workflow method including LIBS } \\
\text { measurement" etc. So re-phrase this statement to reflect better what you have } \\
\text { developed rather than implemented at this stage. }\end{array}$ & Revised. \\
\hline 2. & 2/lines 37, 40 and 140: "tons" instead of "Te"? & Corrected. \\
\hline 3. & 3/ line 40: "Over" instead of ">" (just word it) & Corrected. \\
\hline 4. & 4/ lines 136 and 137: "into" instead of "in to" & Lines $137 \& 138$ corrected. \\
\hline 5. & $\begin{array}{l}5 / \text { line 149: "...adjustment range of } \pm 7.5 \mathrm{~mm} . . . " \text { Do you mean that is your depth of field } \\
\text { and the beam is more or less focused within this } 15 \mathrm{~mm} \text { range? Otherwise, maybe } \\
\text { specify whether the laser beam was focused on the samples' surface or behind it. }\end{array}$ & Yes, addressed in lines 151-152. \\
\hline 6. & $\begin{array}{l}\text { 6/ line } 164 . \text { Is reference [23], Mansoori's paper on "quantitate analysis of cement } \\
\text { powder by laser-induced breakdown spectroscopy" the one you mean to refer to } \\
\text { regarding time delays for carbon measurement? As the paper appears to focus on } \mathrm{Ca}, \mathrm{Si} \text {, } \\
\mathrm{K}, \mathrm{Mg}, \mathrm{Al}, \mathrm{Na}, \mathrm{Ti}, \mathrm{Mn} \text { and } \mathrm{Sr} \text {. }\end{array}$ & Line 164 correct reference used. \\
\hline 7. & $\begin{array}{l}\text { 7/ In the 'Experimental methods' section, indicate whether the measurements were } \\
\text { taken on a flat surface from cut sections of the samples, or not. It appears to be the case } \\
\text { from the photographs in Fig. } 1 \text { but please state it whether it is or not. The plane of } \\
\text { measurement on the charcoal sample is possibly rougher. }\end{array}$ & Revised lines $175-6$ and 179. \\
\hline 8. & $\begin{array}{l}\text { 8/ Overall, measurements seemed to be have been carried out on three samples types: } 1 \text { / } \\
\text { the pre-irradiated graphite, } 2 / \text { the uncompressed lump of charcoal and } 3 / \text { the crushed, } \\
\text { homogenised and pressed charcoal. It is unclear whether the two types of charcoal } \\
\text { samples kept being used or not, as form Fig. } 5 \text { it is referred to as "charcoal" only. Be more } \\
\text { specific and if one of the sample type was not used anymore, please state it. }\end{array}$ & $\begin{array}{l}\text { "Crushed compressed", and "uncompressed" now } \\
\text { added to the relevant mentions of charcoal } \\
\text { throughout the document. }\end{array}$ \\
\hline
\end{tabular}




\begin{tabular}{|c|c|c|}
\hline Item & Reviewers' feedback & Authors' comments \\
\hline 9. & $\begin{array}{l}\text { 9/ lines 174-175: it is stated that more compressed charcoal samples were used and that } \\
\text { conditioning laser shots followed by ten pulses of measurement shots were used. What } \\
\text { is the rationale for deviating from the original single-shot measurement? Explain please. } \\
\text { It also means that the experiment is potentially less representative of a real-life situation } \\
\text { where single-shot measurements were to be used. }\end{array}$ & $\begin{array}{l}\text { Cleaning shots were used in case any contaminants } \\
\text { had been introduced from the pressing process onto } \\
\text { the pellet surfaces, as it was not possible to } \\
\text { otherwise clean the pellet surface. }\end{array}$ \\
\hline 10. & $\begin{array}{l}\text { 10/ line 179: please remove "also" as the energy values tested are different: } 90 \mathrm{~mJ} \text { is not } \\
\text { being tested anymore. Any reason for this? Many of the conclusions later on refer to } \\
\text { what happens for energies below } 100 \mathrm{~mJ} \text { and at } 90 \mathrm{~mJ} \text { whereas this value was not used } \\
\text { anymore in the latter experiments. }\end{array}$ & Line 180 revised. \\
\hline 11. & $\begin{array}{l}\text { 11/ lines 235-236: the following statement "... with varying relative intensity apparent as } \\
\text { the composition changes across the sample." is possibly questionable. The graphs in Fig.3 } \\
\text { display the twelve spectra obtained, without any normalisation of the intensity as far as I } \\
\text { understand. Therefore, how can you be sure the variation in intensities between the } \\
\text { various spectra illustrate the chemical variation across the samples? Given that the } \\
\text { whole wavelength range of each spectra appears to increase and decrease from one } \\
\text { spectra to the other, the effect observed could be due to different volumes ablated at } \\
\text { each of the twelve laser shots. It could also be a combination of chemical variation across } \\
\text { the sample and shot-to-shot ablation variation. There is nothing here to confirm one or } \\
\text { the other. If you have other evidence, please state it. Have you checked the ablated } \\
\text { volumes under a microscope for example? }\end{array}$ & $\begin{array}{l}\text { Microscope checks were not undertaken as there } \\
\text { was no way of accurately targeting an area observed } \\
\text { under a microscope, due to the setup of the LIBSCAN } \\
100 . \\
\text { The PCA analysis included Normalisation integral to } \\
\text { the method; the Figures are meant to illustrate } \\
\text { changes but the principle data evaluation was } \\
\text { statistical. PCA took into account shot to shot } \\
\text { variability. The measurements included rastered } \\
\text { across samples and this variability is included in the } \\
\text { analysis. } \\
\text { If the chemistry was the same across the sample, the } \\
\text { spectra would be identical once normalised and } \\
\text { these are not (by eye). Thus the variation must be } \\
\text { due to chemical composition variation. }\end{array}$ \\
\hline 12. & $\begin{array}{l}\text { 12/ line } 243: \text { "compositional variations throughout each sample". Same observation as } \\
\text { above in 11/. }\end{array}$ & See response to item 11. \\
\hline 13. & $\begin{array}{l}\text { 13/ Under " } 3.3 \text { Multivariate analysis - PCA", state whether you used the whole spectra } \\
\text { data or selected wavelength ranges early on. I got to understand it was the whole } \\
\text { spectral range reaching line } 290 \text { of the manuscript. }\end{array}$ & Line 254 revised. \\
\hline 14. & $\begin{array}{l}\text { 14/ line 271: Figure } 5(A) \text {. The "(A)" in the figure label as no significance in this } \\
\text { manuscript. Please remove it, unless it is relevant for other documents not provided } \\
\text { here. Same for Figure } 6 \text { (B). }\end{array}$ & Line 277 revised. \\
\hline
\end{tabular}




\begin{tabular}{|c|c|c|}
\hline Item & Reviewers' feedback & Authors' comments \\
\hline 15. & $\begin{array}{l}15 \text { / from the 2D PCA plot, the segregation obtained for } 50 \mathrm{~mJ} \text { is the only one to not } \\
\text { display any overlap. Worth mentioning? }\end{array}$ & Line 278 revised. \\
\hline 16. & 16/ line 284: Please correct the figure number in the text. Figure 6, instead of Figure 7. & Corrected. \\
\hline 17. & $\begin{array}{l}\text { 17/ Line 289: unless I am mistaken by not distinguishing properly the colours on the } \\
\text { graph, points not included into the } 95 \% \text { confidence interval ellipses belong to all the } \\
\text { conditions tested, not just the } 100 \mathrm{~mJ} \text { one. }\end{array}$ & $\begin{array}{l}\text { The colours are distinguished on the plot, and they } \\
\text { do align with the } 100 \mathrm{~mJ} \text { results. } \\
\text { The data points not included in the } 95 \% \text { confidence } \\
\text { interval ellipses do indeed belong to all conditions } \\
\text { tested, not just the } 100 \mathrm{~mJ} \text { conditions. We say that } \\
\text { most of the points are. }\end{array}$ \\
\hline 18. & $\begin{array}{l}\text { 18/ line 301: "Loadings in PC1 emphasise the different background levels in the six } \\
\text { spectrometers used in the LIBS experimental setup." Do you also see a difference in the } \\
\text { background between the two matrices, graphite and charcoal? Because of their structure } \\
\text { difference, the charcoal might come with a higher background level that could be useful } \\
\text { to distinguish both matrices possibly? }\end{array}$ & $\begin{array}{l}\text { Background levels were different (background in } \\
\text { terms of the areas to the side of sample peaks), } \\
\text { which is why they showed up in PCA1. The reviewer } \\
\text { is correct that this could have been used as a means } \\
\text { of discrimination. We did not explore this as such } \\
\text { differences might be a consequence of } \\
\text { instrumentation rather than differences in the } \\
\text { materials. However the chemical changes we picked } \\
\text { up will be reproducible as a discrimination method. }\end{array}$ \\
\hline 19. & $\begin{array}{l}\text { 19/ In Table } 3, \text { Ca is detected in the graphite, with content level of } 1 \mathrm{ppm} \text {, and Ca is not } \\
\text { detected from ablation of the charcoal despite the fact it contains } 600 \text { times more Ca } \\
\text { than the graphite? Different plasma temperature possibly? }\end{array}$ & $\begin{array}{l}\text { Lines } 221-2 \text { added. } \\
\text { Ca added to line } 461 .\end{array}$ \\
\hline 20. & 20/ in Table 3, remove the Word reference error. & Corrected. \\
\hline 21. & $\begin{array}{l}\text { 21/ Throughout the manuscript, the chemical elements are alternatively referred to in } \\
\text { the text by their full name and by their symbol. Maybe choose one or the other for } \\
\text { consistency. }\end{array}$ & Most changed to periodic table labels. \\
\hline
\end{tabular}




\begin{tabular}{|c|c|c|}
\hline Item & Reviewers' feedback & Authors' comments \\
\hline 22. & $\begin{array}{l}\text { 22/ lines 342-343: "These results suggest that charcoal and graphite can be differentiated } \\
\text { at } 10-90 \mathrm{~mJ} \text { ns laser pulse energies but not at } 100 \mathrm{~mJ} \text {. Indeed, from the dendrogram, the } \\
\text { data obtained at } 10 \mathrm{~mJ} \text { appeared to be the least reliable. A few data obtained with } 90 \\
\text { and } 50 \mathrm{~mJ} \text { are also in the overlap zone. In the end, only the data obtained at } 10 \mathrm{~mJ} \text { have } \\
\text { no data in the overlap zone. Worth mentioning? }\end{array}$ & $\begin{array}{l}\text { Lines } 347-353 \text { changed. } \\
\text { The reviewer is thanked for this comment. We agree } \\
\text { that it is indeed worth mentioning that there are a } \\
\text { few data with } 90 \text { and } 50 \mathrm{~mJ} \text { also in the overlap zone, } \\
\text { but none for } 10 \mathrm{~mJ} \text {. We were not quite sure whether } \\
\text { the reviewer is referring to the reliability of the data } \\
\text { per se, or the reliability of the result in enabling the } \\
\text { assessment of differentiation between graphite and } \\
\text { carbon. If the latter, we believe that the lack of data } \\
\text { at } 10 \mathrm{~mJ} \text { within the overlap zone suggests that these } \\
\text { data are perhaps the most reliable (i.e. } \\
\text { differentiation at } 10 \mathrm{~mJ} \text { appears to be unequivocal), } \\
\text { as opposed to being least reliable as the reviewer } \\
\text { suggests (if we have interpreted the reviewer's } \\
\text { comment correctly). } \\
\text { However, the presence of a limited number of results } \\
\text { at } 50 \text { and } 90 \mathrm{~m} \text { Jithin the overlap zone might } \\
\text { suggest that the overall picture of differentiation at } \\
50 \text { and } 90 \mathrm{~mJ} \text { is perhaps not unequivocal - i.e. less } \\
\text { reliable than the } 10 \mathrm{~mJ} \text { or } 100 \mathrm{~mJ} \text { results (the } \\
\text { indication of lack of differentiation at } 100 \mathrm{~mJ} \text { appears } \\
\text { to be unequivocal). This helpfully supports the view } \\
\text { that more supporting evidence of differentiation (or } \\
\text { not) at the various laser energies, which we describe } \\
\text { later in the paper, is required. We have revised our } \\
\text { text accordingly and thank the reviewer for } \\
\text { highlighting this. }\end{array}$ \\
\hline 23. & $\begin{array}{l}\text { 23/ line } 372: \text { "These results show that CN formation in charcoal did not occur until } 100 \mathrm{~mJ} \\
\text { pulse energies." From the experiment, it can be concluded that CN formation take place } \\
\text { at least up to } 50 \mathrm{~mJ} \text { and does not happen at } 100 \mathrm{~mJ} \text {. There is no data available between } \\
50 \text { and } 100 \mathrm{~mJ} \text {. Please change a little your statement to reflect this. It is a shame that } 90 \\
\mathrm{~mJ} \text { was not used anymore at this stage. }\end{array}$ & Lines 381-383 revised. \\
\hline
\end{tabular}




\begin{tabular}{|c|c|c|}
\hline Item & Reviewers' feedback & Authors' comments \\
\hline 24. & $\begin{array}{l}\text { 24/ lines 373-375: statement that discrimination relying on the formation of } \mathrm{CN} \text { is } \\
\text { possible up to } 90 \mathrm{~mJ} \text {. Again, there is no data to support this. Results only showed it up to } \\
50 \mathrm{~mJ} \text { (Fig.9), unless I am mistaken. }\end{array}$ & $\begin{array}{l}\text { True, at some energy between } 50 \text { and } 100 \mathrm{~mJ} \text { these } \\
\text { peaks would have started to appear but we only used } \\
3 \text { energies. We have made a slight revision to lines } \\
\text { 386-7. }\end{array}$ \\
\hline 25. & $\begin{array}{l}\text { 25/ lines } 388-393 \text { In the statement on CN violet series peaks being only present in the } \\
\text { LIBS spectrum for charcoal at } 100 \mathrm{~mJ} \text {. Again, there is no data to show is they would have } \\
\text { appeared at lower energies, between } 50 \text { and } 100 \mathrm{~mJ} \text {. Please adjust a little your } \\
\text { statement. }\end{array}$ & $\begin{array}{l}\text { True, at some energy between } 50 \text { and } 100 \mathrm{~mJ} \text { these } \\
\text { peaks would have started to appear but we only used } \\
3 \text { energies. We have made a slight revision. Lines } 401 \\
\text { and } 406 \text { revised. }\end{array}$ \\
\hline 26. & $\begin{array}{l}\text { 26/ line 442: again, not sure this illustrated (only) the compositional variation within each } \\
\text { material. }\end{array}$ & See response to item 11 for the authors' response. \\
\hline 27. & $\begin{array}{l}\text { 27/ line 456: "In-situ analysis is certainly possible, and the analysis can be undertaken in } \\
\text { ambient air". Isn't it an assumption to conclude that in-situ analysis will be possible at } \\
\text { this stage of development? The current development was carried out in a laboratory } \\
\text { environment, on clean samples it seems. Will not real situation samples be covered with } \\
\text { liquids or other source of contamination? This could completely alter the outcome of this } \\
\text { development. The work done is very promising but I cannot see how the statement } \\
\text { above can be done at this stage. }\end{array}$ & $\begin{array}{l}\text { Suggested changes made to lines } 469-70 \text { to remove } \\
\text { 'in-situ' }\end{array}$ \\
\hline 28. & 28/ line 463: "than" instead of "that". & Line 477 corrected. \\
\hline 29. & $\begin{array}{l}\text { 29/ line 492: again } 90 \mathrm{~mJ} \text { given as the value above which the segregation will not work } \\
\text { but a large part of the experiment showed this up to } 50 \mathrm{~mJ} \text { only. Either the data exist to } \\
\text { conclude this work up to } 90 \mathrm{~mJ} \text {, or this value needs to be taken down to } 50 \mathrm{~mJ} \text {. }\end{array}$ & $\begin{array}{l}\text { Figure } 12 \text { revised. } \\
\text { See response to item } 22 .\end{array}$ \\
\hline 30. & $\begin{array}{l}\text { 30/ Figure 12. How can sodium be used in the decision tree as described in Figure 12? As } \\
\text { sodium appeared to display a strong peak in either graphite or charcoal according to Fig.2 } \\
\text { and Table } 3 \text {. It appears contradictory that no sodium detection is associated with the } \\
\text { graphite sample. On the other hand, the sodium content of graphite is } 1 \mathrm{ppm} \text {, which } \\
\text { would tie in with the logic in Fig 12, but not with the information given in Fig. } 2 \text { and Table } \\
\text { 3. Please explain. }\end{array}$ & $\begin{array}{l}\text { Reassessment of the significant presence of } \mathrm{Na} \text { in the } \\
\text { graphite sample leads us to believe that this was due } \\
\text { to contamination. The logical step involving } \mathrm{Na} \text { has } \\
\text { been removed from figure } 12 \text { to reflect this; and } \\
\text { removed from the conclusions, line } 504 \text {. }\end{array}$ \\
\hline 31. & Minor comment & \\
\hline
\end{tabular}




\begin{tabular}{|c|c|c|}
\hline Item & Reviewers' feedback & Authors' comments \\
\hline 32. & $\begin{array}{l}\text { rephrase line 42-43: The inventory of these materials may also is also likely to grow in volume } \\
\text { due to the } 43 \text { future use of high temperature reactors, such as pebble bed modular reactors } \\
103-105 \text { reduction in time compared to what technique? }\end{array}$ & $\begin{array}{l}\text { Line } 42 \text { revised. } \\
\text { Line } 103-105: \text { Other techniques are simply not } \\
\text { available if has to be characterised in-situ. Hence a } \\
\text { historical reliance on sample extraction to test } \\
\text { elsewhere (e.g. mass spectrometry), or inference } \\
\text { from available sampling points e.g. liquor purge, } \\
\text { historical records, and possibly radioactive decay } \\
\text { calculations. } \\
\text { Sample routes are very often unavailable e.g. these } \\
\text { have to have an agreed waste stream opened up that } \\
\text { has regulatory approval. There is significant cost } \\
\text { associated with setting up new approved waste } \\
\text { routes. }\end{array}$ \\
\hline 33. & $\begin{array}{l}\text { line } 179 \text { should be extended to include the total number of spectra collected for the purpose } \\
\text { of this study }\end{array}$ & $\begin{array}{l}\text { A total of } 192 \text { experiments were undertaken. This } \\
\text { has been added to line } 182 .\end{array}$ \\
\hline 34. & line 430-431 claim should have reference & Line 424 revised instead. \\
\hline 35. & 463 line that $->$ than & Line 477 revised \\
\hline 36. & 464 revise & Line 477-9 revised \\
\hline 37. & revise 484 and/or 486 (however used twice) & Line 499 revised \\
\hline 38. & 499 delete is certainly possible or revise sentence & Line 514 revised \\
\hline 39. & $\begin{array}{l}499-501 \text { delete final sentence if there is no reference and no further explanation how PLS-DA } \\
\text { would be used }\end{array}$ & Line 516 reference added \\
\hline 40. & Major comments & \\
\hline 41. & An image of the laser system should be added to the paper to demonstrate its 'portability' & $\begin{array}{l}\text { For commercial reasons we have chosen not to } \\
\text { display the LIBSCAN } 100 \text {. If any readers is interested } \\
\text { in following up on this Google image search will } \\
\text { provide quite a few images. }\end{array}$ \\
\hline 42. & $\begin{array}{l}\text { Figure 9: would be more informative to see a comparison graph of both spectra on the same } \\
\text { scale. }\end{array}$ & $\begin{array}{l}\text { The details for Charcoal would be lost on the } \\
\text { graphite data scale, hence these are deliberately kept } \\
\text { separate. }\end{array}$ \\
\hline
\end{tabular}




\begin{tabular}{|c|c|c|}
\hline Item & Reviewers' feedback & Authors' comments \\
\hline 43. & $\begin{array}{l}\text { Have the authors looked into distinguishing different types of graphite used in different } \\
\text { reactor types as they hint towards in the introduction? }\end{array}$ & $\begin{array}{l}\text { No, this was a differentiation between graphite and } \\
\text { other "non - graphite" carbonaceous waste, this } \\
\text { graphite is of known nuclear industry use so is } \\
\text { significant to the industry's challenge. It is not } \\
\text { necessarily representative of all nuclear graphites, } \\
\text { but we had limited access to clean nuclear grade } \\
\text { graphite. }\end{array}$ \\
\hline 44. & $\begin{array}{l}\text { It is clear that the spectra shown in the figures of this paper were averages of } 10 \text { spectra } \\
\text { collected, but have the authors given a value of the uncertainty (at least e.g. for the major } \\
\text { comparison wavelengths?) }\end{array}$ & $\begin{array}{l}\text { No we haven't as the LIBSCAN system does not } \\
\text { present uncertainty on its data. } \\
\text { PCA analysis is designed around uncertainty, } \\
\text { identifying what is different to random variation. } \\
\text { As the results are qualitative (no PLS-DA for } \\
\text { instance), we do not include results - such as "mean } \\
+/-1 \text { SD. }\end{array}$ \\
\hline 45. & $\begin{array}{l}\text { Paper not really conclusive: lines } 492-496 \text { should quantify how good the multivariate analysis } \\
\text { is in discerning between the different materials }\end{array}$ & $\begin{array}{l}\text { "How good" is done through the use of calibrated } \\
\text { materials. We are only at a "does this work at the } \\
\text { conceptual experiment stage", so a long way away } \\
\text { yet from validation testing. }\end{array}$ \\
\hline 46. & $\begin{array}{l}\text { The paper seems to lack some history on how the discrimination between graphite and } \\
\text { charcoal (or different types of graphite) has been conducted in the past (i.e. only LIBS or } \\
\text { perhaps XRF?). Using what techniques and why is LIBS more advantageous? }\end{array}$ & $\begin{array}{l}\text { The aim of the study was not looking to } \\
\text { discrimination between graphite types. The industry } \\
\text { has no real need for that, whereas between graphite } \\
\text { and charcoal impacts on the bottom line cost for UK } \\
\text { plc. How have we discriminate at present - visual } \\
\text { inspection, historical records, and location. }\end{array}$ \\
\hline 47. & There wasn't an author list anywhere. & $\begin{array}{l}\text { This was supposed to be double blind so author } \\
\text { details were deliberately omitted, as required by } \\
\text { Elsevier }\end{array}$ \\
\hline
\end{tabular}




\begin{tabular}{|c|c|c|}
\hline Item & Reviewers' feedback & Authors' comments \\
\hline 48. & $\begin{array}{l}\text { This article details the use of LIBS to identify nuclear grade graphite vs. other carbon species. } \\
\text { The paper is well written, explained, and cited. I think the authors are claiming something } \\
\text { they cannot deliver on. However, the work/science seem to be sound. If the authors want to } \\
\text { tone back the "LIBS is the greatest for this problem" and present it more as a study on LIBS } \\
\text { and graphite/charcoal preliminary study, it would be more appropriate for publishing. }\end{array}$ & $\begin{array}{l}\text { The authors don't believe the paper says LIBS is the } \\
\text { greatest. } \\
\text { We have now amended the title as a new approach. } \\
\text { Lines } 28-29 \text { refer to the characterisation benefits LIBS } \\
\text { offers vs the challenges/constraints. } \\
\text { Lines } 100-106 \text { explains the aim of the assessment of } \\
\text { LIBS for the challenge. } \\
\text { Line } 333 \text { 'outcome' revised to 'aim'. }\end{array}$ \\
\hline 49. & $\begin{array}{l}\text { I still, however, am left with some doubt if this will actually work in a non-laboratory } \\
\text { setting. The authors used just one piece of graphite and one piece of charcoal, both of which } \\
\text { have large geochemical variations. This is even more of an issue when it comes to identifying } \\
\text { impurities in each species of carbon variant. }\end{array}$ & $\begin{array}{l}\text { The paper is an investigation into the differentiation } \\
\text { between both material types, with a view to a real } \\
\text { world problem; as were identified prior to the } \\
\text { development of other real world characterisation } \\
\text { challenges. Transfer from a laboratory setting to a } \\
\text { non-laboratory setting would have been seen as } \\
\text { equally challenging for these now established non- } \\
\text { laboratory settings, which provides evidence that } \\
\text { similar paths out of the laboratory could be } \\
\text { established for this discrimination. } \\
\text { Using PCA the large geochemical variations did not } \\
\text { present a problem in differentiation between } \\
\text { samples. } \\
\text { This work says that "there is a difference in LIBS data } \\
\text { charcoal and graphite and we think this might be the } \\
\text { basis for screening differentiation of carbonaceous } \\
\text { waste materials"; it is not "this shows how we have } \\
\text { calibrated LIBS to make this screening work" - lots of } \\
\text { work to get from one to the other. }\end{array}$ \\
\hline
\end{tabular}




\begin{tabular}{|c|c|c|}
\hline Item & Reviewers' feedback & Authors' comments \\
\hline 50. & $\begin{array}{l}\text { Similarly, at a distance of } 7.5 \mathrm{~mm} \text {, what is the practical application of this if people aren't } \\
\text { allowed inside a reactor to perform these measurements at a distance of mm anyway? }\end{array}$ & $\begin{array}{l}\text { The ex-situ analysis of waste streams from in-situ. It } \\
\text { is not beyond the realms of possibility of introducing } \\
\text { fibre based LIBS into an unloaded reactor's core } \\
\text { during decommissioning? } \\
\text { Deploying LIBS over distance is commonly achieved, } \\
\text { and widely reported in literature. } \\
\text { Lines } 27-8 \text { specifically state a waste stream. }\end{array}$ \\
\hline 51. & $\begin{array}{l}\text { Also, given the step } 3 \text { in figure 12: "molecular emission analysis to confirm graphite or non- } \\
\text { graphite waste" doesn't make LIBS the defining technique for this approach. }\end{array}$ & $\begin{array}{l}\text { The author's do not claim that this approach is the } \\
\text { defining technique for molecular emission analysis. } \\
\text { The investigation is to ascertain whether or not LIBS, } \\
\text { that has the potential to be deployed in the industrial } \\
\text { locations required, can be used to distinguish } \\
\text { between graphite and other carbonaceous wastes. } \\
\text { We did not say it was the only method: but the } \\
\text { observed differences are a new finding that suggests } \\
\text { that LIBS could be used; before this study, we would } \\
\text { have said LIBS was not appropriate. } \\
\text { The paper is about a LIBS-based workflow to } \\
\text { discriminate - i.e. it's the workflow not LIBS itself } \\
\text { that is the defining technique for the approach. }\end{array}$ \\
\hline
\end{tabular}




\begin{tabular}{|c|c|c|}
\hline Item & Reviewers' feedback & Authors' comments \\
\hline 52. & $\begin{array}{l}\text { It seems that if the authors had infinite time and laser experiments, they could distinguish } \\
\text { between the two: i.e., Figure } 11 \text {. However, the paper is trying to sell this technique as the } \\
\text { 'best and fastest' way to do this, and I am not convinced. The authors would need to } \\
\text { characterize a suite of charcoal and graphite samples with their LIBS technique, at the same } \\
\text { wavelength, delay time to make this case valid. Until then they are just claiming something } \\
\text { that cannot be backed up. }\end{array}$ & $\begin{array}{l}\text { We have tried to say that we are looking at the } \\
\text { fundamental science of how, and why, LIBS could be } \\
\text { used, at a screening level, to identify different } \\
\text { materials, rather than just as a black box technique. } \\
\text { It is true that this is not the only technique that you } \\
\text { could use (e.g. portable XRF) and the only data } \\
\text { interpretation method. Our explanation as to why we } \\
\text { want to publish our findings is as follows: We have } \\
\text { shown it is possible for certain molecular peaks from } \\
\text { carbon clusters and CN bonds to arise only in } \\
\text { particular circumstances and that they enable } \\
\text { identification of the difference between two } \\
\text { materials. The pre-work hypothesis would have been } \\
\text { that the two materials should have produced more } \\
\text { or less the same spectra when heated by a plasma } \\
\text { (i.e. mostly atomised/ionised carbon). The findings } \\
\text { here are of intrinsic scientific interest. The carbon } \\
\text { spectral emission lines of interest will not have been } \\
\text { affected by the presence of trace elements, so we } \\
\text { don't think that our findings would be altered by } \\
\text { having many different samples of charcoal and } \\
\text { graphite. We suspect that the differences are due to } \\
\text { the density of carbon packing in the different } \\
\text { materials rather than the material provenance, and } \\
\text { that our new hypothesis is being investigated at the } \\
\text { present time in a follow up study. In other words, we } \\
\text { are focussing on providing answers as to why and } \\
\text { how carbon spectra are different between the two } \\
\text { materials at particular LIBS settings. }\end{array}$ \\
\hline
\end{tabular}




\begin{tabular}{|c|l|l|}
\hline Item & \multicolumn{1}{|c|}{ Reviewers' feedback } & \multicolumn{1}{c|}{ Authors' comments } \\
\hline 53. & $\begin{array}{l}\text { Figures 10,11, and 12 should remove the grey backgrounds. It would give the figures a more } \\
\text { consistent look throughout the paper. }\end{array}$ & Replaced. \\
\hline 54. & Minor comments & $\begin{array}{l}\text { Reference added. } \\
\text { clarification on these would be useful for other people interested in LIBS }\end{array}$ \\
\hline 55. & \\
\hline
\end{tabular}


Key Highlights

- A new approach to graphite waste segregation using LIBS in nuclear decommissioning

- Multivariate analysis of LIBS spectra enables identification of graphite

- $\quad$ LIBS molecular emission fingerprinting key to graphite identification

- $\quad$ Laser pulse (ns) energies $>90 \mathrm{~mJ}$ unsuitable for analysis

- $\quad$ A LIBS analysis workflow for nuclear grade graphite identification is proposed 


\section{Abstract}

Stand-off, in-situ, laser induced breakdown spectroscopy (LIBS) offers a rapid, safe, and costeffective method for discrimination of radioactive waste materials arising during the operation of nuclear plants and from decommissioning activities. Characterisation of waste materials is a critical activity in understanding the nature of the waste, ensuring hazardous material is managed safely and that waste can be segregated for reuse, recycle or sentenced for appropriate disposal. Characterisation of materials, often in hostile environments, requires the ability to remotely differentiate between materials in terms of their chemical composition and radioactivity.

This proposition was tested using a case study on nuclear grade graphite. Graphite has been used extensively as a moderator material in many nuclear reactors. Internationally, over 250,000 tons of various nuclear-grade graphite, and graphite-bearing, materials exist and are a major issue for nuclear decommissioning and radioactive waste management, due to the long half-lives of the associated ${ }^{14} \mathrm{C}$ and ${ }^{36} \mathrm{Cl}$ isotopes. LIBS offers a method for discrimination of nuclear grade graphites and other carbon and non-carbon-bearing wastes. This paper describes the development of a workflow method, including LIBS measurement analysis, for the discrimination of pre-irradiated nuclear 'Pile Grade A' (PGA) graphite moderator rod and domestic lumpwood charcoal, which act as surrogates for nuclear grade graphite and other carbon-bearing wastes. A new analysis workflow comprising the examination of spectral characteristics, multivariate analysis and molecular isotopic spectroscopy is proposed to enable rapid segregation of graphite from a heterogeneous waste stream. Enhanced characterisation techniques have the potential to significantly reduce the cost of decommissioning large parts of legacy nuclear generation plants. 
John. P. O. Horsfalla,b, Divyesh Trivedia,b, Nick. T. Smitha,b,c,e*, Philip A. Martin ${ }^{d}$, Paul Coffey ${ }^{d}$, Stella

Tourniere,f, Anthony Banford ${ }^{\mathrm{a}, \mathrm{d}, \mathrm{e}}$, Lin Li ${ }^{\mathrm{b}}$, David Whitehead ${ }^{\mathrm{b}}$, Adam Lang ${ }^{\mathrm{g}}$ and Gareth. T. W. Law ${ }^{\mathrm{g}}$

aNational Nuclear Laboratory, Chadwick House, Warrington Road, Birchwood Park, Warrington, WA3 6AE, United Kingdom.

bSchool of Mechanical, Aerospace and Civil Engineering, The University of Manchester, Oxford Road, Manchester, M13 9PL, United Kingdom.

'School of Earth, Atmospheric and Environmental Sciences, The University of Manchester, Oxford Road, Manchester, M13 9PL, United Kingdom.

dSchool of Chemical Engineering and Analytical Sciences, The University of Manchester, Oxford Road, Manchester, M13 9PL, United Kingdom.

eCentre for Innovative Nuclear Decommissioning (CINDe), National Nuclear Laboratory, Workington, Cumbria, CA14 3YQ, United Kingdom.

fSchool of Electronics and Electrical Engineering, The University of Manchester, Oxford Road, Manchester, M13 9PL, United Kingdom.

9Centre for Radiochemistry Research, School of Chemistry, The University of Manchester, Oxford Road, Manchester, M13 9PL, United Kingdom. * corresponding author E-mail address: nick.t.smith@nnl.co.uk (N.T.Smith).

*Telephone: +44 (0) 161306 0514; email: nicholas.smith@manchester.ac.uk

\section{Key Highlights}

- A new approach to graphite waste segregation using LIBS in nuclear decommissioning

- $\quad$ Multivariate analysis of LIBS spectra enables identification of graphite

- $\quad$ LIBS molecular emission fingerprinting key to graphite identification

- $\quad$ Laser pulse (ns) energies $>90 \mathrm{~mJ}$ unsuitable for analysis

- $\quad$ A LIBS analysis workflow for nuclear grade graphite identification is proposed

\section{Abstract}

Stand-off, in-situ, laser induced breakdown spectroscopy (LIBS) offers a rapid, safe, and costeffective method for discrimination of radioactive waste materials arising during the operation of nuclear plants and from decommissioning activities. Characterisation of waste materials is a critical 
activity in understanding the nature of the waste, ensuring hazardous material is managed safely and that waste can be segregated for reuse, recycle or sentenced for appropriate disposal. Characterisation of materials, often in hostile environments, requires the ability to remotely differentiate between materials in terms of their chemical composition and radioactivity.

This proposition was tested using a case study on nuclear grade graphite. Graphite has been used extensively as a moderator material in many nuclear reactors. Internationally, over 250,000 tons of various nuclear-grade graphite, and graphite-bearing, materials exist and are a major issue for nuclear decommissioning and radioactive waste management, due to the long half-lives of the associated ${ }^{14} \mathrm{C}$ and ${ }^{36} \mathrm{Cl}$ isotopes. LIBS offers a method for discrimination of nuclear grade graphites and other carbon and non-carbon-bearing wastes. This paper describes the development of a workflow method, including LIBS measurement analysis, for the discrimination of pre-irradiated nuclear 'Pile Grade A' (PGA) graphite moderator rod and domestic lumpwood charcoal, which act as surrogates for nuclear grade graphite and other carbon-bearing wastes. A new analysis workflow comprising the examination of spectral characteristics, multivariate analysis and molecular isotopic spectroscopy is proposed to enable rapid segregation of graphite from a heterogeneous waste stream. Enhanced characterisation techniques have the potential to significantly reduce the cost of decommissioning large parts of legacy nuclear generation plants.

\section{Keywords}

LIBS fingerprinting; i-graphite; decommissioning; waste management. 
1 A new analysis workflow approach for discrimination of nuclear grade graphite using laser-

2 induced breakdown spectroscopy

3 Key Highlights

- A new approach to graphite waste segregation using LIBS in nuclear decommissioning

- $\quad$ Multivariate analysis of LIBS spectra enables identification of graphite

- $\quad$ LIBS molecular emission fingerprinting key to graphite identification

- $\quad$ Laser pulse (ns) energies $>90 \mathrm{~mJ}$ unsuitable for analysis

- $\quad$ A LIBS analysis workflow for nuclear grade graphite identification is proposed

\section{Abstract}

Stand-off, in-situ, laser induced breakdown spectroscopy (LIBS) offers a rapid, safe, and cost-effective method for discrimination of radioactive waste materials arising during the operation of nuclear plants and from decommissioning activities. Characterisation of waste materials is a critical activity in understanding the nature of the waste, ensuring hazardous material is managed safely and that waste can be segregated for reuse, recycle or sentenced for appropriate disposal. Characterisation of materials, often in hostile environments, requires the ability to remotely differentiate between materials in terms of their chemical composition and radioactivity.

This proposition was tested using a case study on nuclear grade graphite. Graphite has been used extensively as a moderator material in many nuclear reactors. Internationally, over 250,000 tons of various nuclear-grade graphite, and graphite-bearing, materials exist and are a major issue for nuclear decommissioning and radioactive waste management, due to the long half-lives of the associated ${ }^{14} \mathrm{C}$ and ${ }^{36} \mathrm{Cl}$ isotopes. LIBS offers a method for discrimination of nuclear grade graphites and other carbon and non-carbon-bearing wastes. This paper describes the development of a workflow method, including LIBS measurement analysis, for the discrimination of pre-irradiated nuclear 'Pile Grade A' (PGA) graphite moderator rod and domestic lumpwood charcoal, which act as surrogates for nuclear grade graphite and other carbon-bearing wastes. A new analysis workflow comprising the examination of spectral characteristics, multivariate analysis and molecular isotopic spectroscopy is proposed to enable rapid segregation of graphite from a heterogeneous waste stream. Enhanced characterisation 
techniques have the potential to significantly reduce the cost of decommissioning large parts of legacy nuclear generation plants.

\section{Keywords}

LIBS fingerprinting; i-graphite; decommissioning; waste management.

\section{INTRODUCTION}

Graphite, a crystalline allotrope of carbon, is used across the world as a neutron moderator and reflector in nuclear reactors. This results in an accumulation of radioactivity by neutron activation of both the constituent elements of graphite, of impurities, as well as potential contamination of its surface, producing i-graphite [1]. The current global inventory of i-graphite, is in excess of 250,000 tons. The management of large quantities of i-graphite is a significant decommissioning and waste disposal challenge, due to the long half-lives of the associated ${ }^{14} \mathrm{C}$ and ${ }^{36} \mathrm{Cl}$ isotopes, and is the subject of international research [2][3][4][5][6][7]. The current legacy includes over 250,000 tons of i-graphite, as well as a range of related carbon bearing materials resulting from typical i-graphite decontamination processes [1]. The inventory of these materials is also likely to grow in volume due to the future use of high temperature reactors, such as pebble bed modular reactors [7][8].

Safe and rapid characterisation of multiple forms of i-graphite, graphite-bearing materials, and mixed waste streams of these materials, alongside materials that contain no graphite or carbon, is of importance to cost effective nuclear decommissioning. Waste components, such as steels and concrete, can be easily distinguished from graphite. However, the separation of graphite (including the segregation of different nuclear grade graphite's from each other) from other carbon containing materials (e.g. AGR reactor core carbon deposits, incinerator ash, wood, polymers - such as VITON and bitumen) is challenging.

Materials characterisation is required during decommissioning to ensure that waste is handled appropriately, thus helping to minimise dose uptake to the workforce and ensuring that the waste is treated, sentenced, and / or disposed of safely, thus reducing waste volumes to reduce life cycle impacts of decommissioning [9]. Sample retrieval and analysis can be particularly challenging, when one considers mixed wastes (solid and liquid wastes of different material compositions and provenance) 
from historic facilities and waste stores, where materials may have changed physically or chemically during storage.

Much of this waste is found in physically inaccessible locations that provide potentially hazardous environments, and where access to humans is limited, or precluded for safety reasons, increasing the decommissioning challenge [10]. As a consequence, it is not always possible to obtain samples, or do so in adequate numbers to ensure representative characterisation. One way to address this is to undertake in-situ characterisation of graphite (and other potentially hazardous materials) without the need for human intervention, sample collection, preparation, or offsite analysis.

With an ability to rapidly identify the different elemental compositions of materials, at relatively high sensitivity and reliability [11], laser-induced breakdown spectroscopy (LIBS) is a form of atomic emission spectroscopy that uses a high-energy density laser pulse as an excitation source [12][13]. The increasing use of LIBS for elemental analysis in industry and academia [12][13][14][15] includes quality control in the pharmaceutical industries, planetary exploration, and forensic analysis [16][17][18][19][20][21]. It is particularly useful where rapid, multi-element analysis of solids, liquids, and gases [22][23][24][25], with little or no sample preparation, is required. Most LIBS instruments use a $\mathrm{Nd}$ :YAG, or a diode pumped, solid state laser, with a beam wavelength of $1064 \mathrm{~nm}$ [26] focused onto the surface of a sample to provide the excitation source. The fast expansion and cooling of the resulting high-density plasma, produced by the heating of material ablated from the surface at the focus of the laser beam, induces the release of radiation characteristic of the chemical composition of the sample. This is monitored by a detection instrumentation (including a spectrometer) that measures the wavelength and intensity of the emission [27]. Since all elements will emit a characteristic emission spectrum on cooling of the plasma, and indeed some molecular species will provide characteristic emissions, theoretically LIBS has the ability to identify many substances, no matter whether they are in solid, liquid, gas, or aerosol states. Emission lines collected by the spectrometer can be identified using appropriate software and emission spectra databases e.g. NIST [28].

There are some examples of the practical application of LIBS to characterize materials specifically from the nuclear arena in published literature. To date, the successful identification of fission products, actinides, radionuclides, and activated corrosion products has been reported within a range of supporting materials that include mixed oxide fuels [29], vitrified high level waste [30], and molten salt 
electrolytes [31]. These include the use of LIBS to analyse specific radioactive materials such as uranium or plutonium, and radionuclides such as ${ }^{90} \mathrm{Sr}$ and ${ }^{137} \mathrm{Cs}[30][32][33][34][35][36]$.

A number of studies have focussed on the issues surrounding the development and deployment of LIBS instrumentation for remote, in-situ detection of radioactive material inside nuclear plants [37][38]. However, little has been published about the LIBS spectroscopic characteristics of nuclear waste materials common to nuclear decommissioning, including graphite. Myakalwar et al (2015) [39] noted that the utilisation of LIBS for materials identification has been hindered by the lack of robustness of developed classification models, often due to the presence of spurious correlations, but suggested that this may be addressed by algorithm-developed wavelength selection for determining maximally discriminatory features in spectral data (i.e. using subsets of the full LIBS broadband). The most prominent peaks in LIBS spectral data are often not those that provide the most diagnostic utility. The use of algorithms developed from knowledge of a material's composition, and applied to the whole dataset to remove uninformative or spurious data (in some cases up to $99 \%$ of the full dataset [39]), could provide a much increased classification capability based on judicious feature selection.

In this new study, we undertake a range of LIBS analyses to explore the use of multivariate statistical analysis techniques for discriminating between graphite and charcoal, which is used to represent other carbon-bearing materials and represents a challenging test case. Our primary aim is to investigate whether LIBS can be used to distinguish the two different types of carbon based materials. We use our data to define and propose a new analysis workflow that enables rapid, in-situ, analysis of results, which could result in a significant reduction in time (and therefore cost) for decommissioning and waste management.

\section{MATERIALS AND METHODS}

\subsection{Material choice and sample preparation}

A number of nuclear grade graphites have been produced for UK reactors [40], corresponding to different reactor designs. All the UK's Magnox reactors are closed and currently being decommissioned. All of the UK's Advanced Gas Cooled (AGR) reactors are still in operation, and therefore most graphite waste in the UK is currently within Magnox power stations. These used 'Pile Grade A' (PGA) graphite, derived from petroleum [41] and created by extrusion of 'needle' coke [40]. AGR reactors used 
113 Gilsocarbon graphite, which was developed from the extrusion of Gilsonite coke, produced from the refining of asphalt [41]. In this study we used compressed un-irradiated PGA graphite.

115 Aside from impurities accumulated during a reactor's operational phase, nuclear-grade moderator graphite also has a number of inherent impurities present within its matrix. Whilst this is the case for all nuclear grade graphites, it should be noted that composition does vary across different graphite grades. For instance, Ancius et al (2005) [42] noted that the largest components of RBMK-1500 graphite (used in many Russian reactors) include S (5-52 ppm), Fe (18 ppm) and $\mathrm{Ca}(52 \mathrm{ppm})$ [42], whereas the composition of PGA graphite (for example) is slightly different, with the three largest components being $\mathrm{S}$ (50 ppm), Si, and Ca (both 35 ppm) (Table 1). uncertainties)

Waste streams, derived from the various nuclear grade graphites, are likely to comprise both pure graphites, and mixed waste, where graphite is likely to be one of perhaps several components. With carbon being the dominant element, this study focused initially on the differences in impurity composition as the primary basis for discrimination; using molecular carbon peaks as a secondary differentiator. Several authors suggest that aside from carbon, domestic charcoal contains many different types of hydrocarbons, organic and inorganic chemicals, water, oxygen and other trace elements [8][44][45][46][47], whilst Syred et al [26] note that lumpwood charcoal for Brazilian blast furnaces may contain between 3 and $10 \%$ ash, and, up to $26 \%$ volatile matter, against $75-80 \%$ char (solid carbon). Accordingly, we use a combination of uncompressed and crushed, sieved, and pressed lumpwood charcoal with the composition listed in Table 2 in this study as a material that is representative of other carbon bearing mixed wastes. For the crushed and sieved graphite, a small portion of a stock lumpwood charcoal was crushed and ground into a powder using a ceramic mortar and pestle. The powder was then sieved into two size groups: $<710 \mu \mathrm{m}$ and $<212 \mu \mathrm{m}$, using test sieves conforming to BS ISO 3310-1:2016 [48]. $1 \mathrm{~g}$ of powder of each grain size group was placed into a $13 \mathrm{~mm}$ diameter die and compressed under force for $5 \mathrm{mins}$, using a Specac hydraulic press. Pellets of each grain size were generated at 10 tons and at 14 tons pressing force. The choice of grain size and pressure was driven by tablet strength: lumpwood charcoal tablets formed from larger grain sizes, or under lower pressures tended to form more weakly bound tablets, which crumbled easily. 


\subsection{Experimental methods}

This study utilised an Applied Photonics Ltd. LIBSCAN 100 comprising a Q-switched Nd:YAG pulsed laser (Quantel Big Sky CFR Ultra GRM) with a fundamental wavelength of $1064 \mathrm{~nm}$, with an ICE 450 liquid cooling group / power supply. The temporal laser beam width was $7 \pm 2 \mathrm{~ns}$, focused to a point approximately $3.5 \mathrm{~mm}$ from the end of a laser head plastic nozzle, using an in-built lens-based beam expander. The factory settings produced a beam focused approximately $3.5 \mathrm{~mm}$ below a sample's surface, for a sample flush with the nozzle [49]. Samples were placed, flush to the nozzle in a small interlocked sample chamber with a moveable X-stage with manual control, allowing the sample to be moved in one direction relative to the laser focus. For multivariate analysis, four laser pulse energies (10 mJ, $50 \mathrm{~mJ}, 90 \mathrm{~mJ}$ and $100 \mathrm{~mJ}$ ) were used in a surrounding atmosphere of air and then nitrogen, to enable assessment of an optimal pulse energy range. For each analysis, a laser pulse with no conditioning was utilised in order to replicate as close as possible, the assumed conditions for in situ analysis of (for example) conveyor-controlled waste streams from decommissioning. The emission from the cooling plasma was collected by plano convex quartz lenses, with focal length of $75 \mathrm{~mm}$, into the entrance slits of six fibre optic spectrometers [49]. The dispersed plasma light was gathered by an inbuilt detector system and converted to spectra covering a LIBS broad-band of $182.88-904.80 \mathrm{~nm}$; this permitted identification of the necessary elements through their unique spectral features.

For most of the study, the pulse to emission capture start delay time was fixed at the equipment minimum of $1.28 \mu \mathrm{s}$ with a gate width of $1.1 \mathrm{~ms}$, based on previous results that have demonstrated that short ( $\leq 10 \mu \mathrm{s})$ delay times yield the most intense signal for carbon and for other elements reported in this work [50]. Samples were placed on a horizontal $X-Y$ sample stage. For multivariate analyses, single shot spectra with no conditioning shots were gathered at the four energy levels noted, in a gas purge of air and then of nitrogen. For each energy level, and in each of the two gases, each sample was moved to a new location using the $\mathrm{X}-\mathrm{Y}$ stage, so that an emission was gathered from twelve locations along the sample (Figure 1).

Figure 1 (A) Sample of pre-irradiated graphite showing locations of LIBS shots; (B) sample of uncompressed lumpwood charcoal showing locations of LIBS shots.

The same graphite sample was analysed using the experimental set up described above, resulting in no discernible damage to its flat surface. However, the uncompressed charcoal suffered damage to its 
rough surface (due to the friability of charcoal), so further additional samples of crushed compressed charcoal (prepared as described above) were then used. Here, rather than a single shot with no conditioning, three conditioning laser pulses were followed by analysis averaged over ten pulses to its flat surface (the number of analysis pulses were limited to ten to avoid full penetration of the sample by the laser). Additionally (to explore optimal experimental set ups) the delay time was increased in ten steps from $1.28 \mu$ s to $6 \mu \mathrm{s}$ (still with a gate width of $1.1 \mathrm{~ms}$ ). Laser pulse energy was increased in three steps of 25,50 and $100 \mathrm{~mJ}$. A total of 192 experiments were undertaken.

\section{RESULTS}

\subsection{Charcoal analysis}

The composition of the charcoal used is presented in Table 2.

Table 2 Elemental composition of domestic lumpwood charcoal impurities determined using XRF. The instrumental error associated with the reported results above was calculated as $0.33 \%$ (1 SD), based on 10 repeated analyses of the river bed standard GBW07311.

\subsection{Spectral analysis}

Figure 2 shows the initial LIBS spectra for graphite moderator rod and uncompressed lumpwood charcoal, collected at $100 \mathrm{~mJ}$ and using a delay time of $1.28 \mu \mathrm{s}$. Spectral peak matching, where signature peaks with different wavelengths represent particular elements, was used to show the similar bulk compositions of carbon-bearing waste materials, and to attempt initial elemental identification. The key atomic and molecular emission lines identified in spectra obtained are summarised in Table 3. Analysis was undertaken in air so, as expected, spectral lines from atomic and molecular nitrogen and oxygen were observed between $750-850 \mathrm{~nm}$ in all spectra for both materials.

Figure 2 LIBS spectra for uncompressed charcoal and graphite at $100 \mathrm{~mJ}$ pulse energy and $1.28 \mu$ selay time.

Clear atomic $C(I)$ lines are present at $193.09 \mathrm{~nm}$ and $247.86 \mathrm{~nm}$ within the graphite spectrum (Figure 2, labels (i) and (ii)), but these are lost in noise in the charcoal spectrum and thus were not useful for this study. Lines representing molecular carbon were also identified, allowing further analysis using molecular isotopic spectroscopy [51], as described later. This includes several sets of molecular emissions from $\mathrm{C}_{2}$ [52]; the most distinctive set includes the $516 \mathrm{~nm}$ line at the head of the 
Swan system $(0,0)$ group of transitions (Figure 2 label (iii)), and the $619 \mathrm{~nm}$ line, representing the head of the Swan system $(0,2)$ group of transitions (Figure 2 label (iv)). Of the distinctive molecular emissions from $\mathrm{CN}$ species, the $\mathrm{CN}$ line in at $358.58 \mathrm{~nm}$ [53] (Figure 2 label (v)) is much greater for graphite moderator material than for charcoal.

The lines representing the Violet $\mathrm{CN}$ series with its band head at $388 \mathrm{~nm}$ (Figure 2 label (vi)) can be readily identified. These occur when carbon bearing materials containing nitrogen are ablated, and from atomic carbon recombining with nitrogen in air [51]. Other studies [50][54] have investigated the formation of $\mathrm{CN}$ groups by atomised carbon and nitrogen in air utilising high resolution spectrometers and femtosecond delay times, and such studies may provide better understanding of atomic and molecular carbon reaction pathways.

Three peaks present in graphite at $279.65 \mathrm{~nm}, 280.26 \mathrm{~nm}$ and $285.23 \mathrm{~nm}$ (Figure 2 labels (vii)-(ix) respectively) are likely to be of $\mathrm{Mg}(\mathrm{II})$ (representing the $2 \mathrm{p}^{6} 3 \mathrm{~s}$ to $2 \mathrm{p}^{6} 3 p$ transition) [53]. Taking into account the $1.28 \mu$ s delay time it is unlikely that the distinct, high intensity lines at $393.4 \mathrm{~nm}$ and $396.9 \mathrm{~nm}$ (Figure 2 label $(\mathrm{x})$ ) in both spectra represent $\mathrm{C}(\mathrm{III})$ and $\mathrm{C}(\mathrm{IV})$ transitions (which may be possible for a shorter delay time, or higher laser energy). Instead, these are more likely to represent $\mathrm{Ca}(\mathrm{II})$, which is the largest of the impurities present in both materials and corresponds to the $3 p^{6} 4 \mathrm{~s}$ to 3p64p transition of Chamberlain (2012) [55]. Despite a lower Ca content in graphite the associated higher intensity peak for $\mathrm{Ca}$ is theorised as being due to a hotter plasma for graphite. Spectral lines representing $\mathrm{Na}(\mathrm{I})$ are also readily identified in both spectra, including the classic doublet at $588.98 \mathrm{~nm}$ and $589.54 \mathrm{~nm}$ (Figure 2 label (xi)). A summary of lines, their relevant transitions and wavelengths for graphite moderator and lumpwood charcoal is provided in Table 3.

\section{Table 3 Elemental and molecular lines examined in this study.}

Rastering across each sample provides a more comprehensive dataset, and also allows visual examination of the composition of moderator graphite compared to charcoal, and of the variations in composition within each sample. Spectra for the twelve laser shot locations for each sample are shown in Figure $3 \mathrm{~A}$ and $\mathrm{B}$. 
Figure 3 Visualisation of the variations in spectra obtained from twelve locations on each sample of (A) graphite moderator and (B) uncompressed lumpwood charcoal.

'Chamberlain's peaks', representing the $3 p^{6} 4 s-3 p^{6} 4 p$ transition of $\mathrm{Ca}(\mathrm{II})$ within graphite [55], are visible at $393.37 \mathrm{~nm}$ and $396.85 \mathrm{~nm}$ (Figure $3 \mathrm{~A}(\mathrm{i})$ ). Here the relative intensity is low, compared to (for example) the nitrogen and oxygen atomic lines (from air) at the other end of the spectrum. There is little variation of relative intensity, (illustrating the amount of Ca present as an impurity within graphite) across the sample. However, at the same location for charcoal (Figure 3 B (i)) they appear not to be present at all so no variation can be seen. The $\mathrm{Ca}(\mathrm{I})$ line at $422.67 \mathrm{~nm}$ ((ii) in Figure $3(\mathrm{~A})$ and (B)), however is visible in the spectra for both samples, with varying relative intensity apparent as the composition changes across the sample. The $\mathrm{Fe}(\mathrm{I})$ lines visible at $610.22 \mathrm{~nm}$, and $612.03 \mathrm{~nm}$ (see Table 3) are also identifiable in the graphite spectra, and it is possible to trace the variation in the relative intensity of both lines across the graphite sample (Figure $3 \mathrm{~A}$ (iii)). However, the large number of lines visible at that wavelength in the spectra for lumpwood charcoal, mean it is difficult to identify both of the lines and any variation across the sample (Figure $3 \mathrm{~B}$ (iii)).

Therefore, initial analysis of spectral peaks on a 2D graph proved of some use in identifying some the key components and 3D spectra of a raster of locations from each sample enabled visual observation of compositional variations throughout each sample. However, neither technique appears to be able to provide suitable information about the actual composition of the sample, and cannot be used for discrimination between materials. No intensity normalisation was undertaken for the instrument response function.

\subsection{Multivariate analysis - Principal Component Analysis (PCA)} For multivariate, principal component analysis (PCA), spectra were analysed, for full spectra, using the CHEMOSPEC package [56] utilised with the R statistical environment [57]. Firstly 'scree plots' were created to identify the most important new variables (principal components, or 'PCs'). These showed the percentage of total variability that could be assigned to each of the new principal components. To provide a robust classification, the Ward's bootstrap method [58] was applied to experimental results to enable both the proportion of the data explained by each principal component to be calculated, and to calculate the uncertainty associated with that assignment. This is shown for the whole dataset in Figure 4. The figure suggests that the first three principal components (PC1-PC3) can clearly explain $>50 \%,>10 \%$, and another $10 \%$ of the variability in the data 
distinctive, providing a unique contribution to sample variability, whereas the remaining PC terms are less distinguishable from each other and make only small contributions to data variability.

Figure 4 Scree plot of the principal components using a bootstrap method (e.g. Ward's [58]) - lines above and below each box represent min-max ranges, indicating $\pm 5 \%$ uncertainty about each mean PC value.

2D 'PCA biplots' were created to compare the behaviour of spectral line components that differentiate between two principal components. These plot the new scores, as recalculated values, for each analysis of two PCs, in different colours. In this study biplots were created for the six combinations of the first three PCs. These represented combinations of specific material type/laser pulse energy in different colours, with coloured ellipses surrounding data points representing a $95 \%$ confidence interval. If all ellipses overlap then it is likely that there is no unique PC1 vs PC2 combination to distinguish between different materials, whereas separation of the ellipses would suggest discrimination between materials. Figure 5 shows an example of the six biplots for PCs 1 and 2 for the two materials at a range of laser pulse energies. With the exception of both materials at $50 \mathrm{~mJ}$, all of the confidence ellipses overlap at least one other material/pulse energy combination, suggesting that there is no unique PC1 vs PC2 combination that can distinguish the different materials. and $100 \mathrm{~mJ}$ laser ns pulse energies.

Figure 6 3D plot of PCs 1, 2, and 3 showing clear separation between groupings of ellipses representing allowed full 3D visualisation of the confidence ellipses (defined using the same $95 \%$ confidence interval), allowing any segregation in the data to be highlighted. This is shown in Figure 6 where it can be seen that the confidence ellipses clearly located in two distinctive groups, based upon whether the sample is charcoal or graphite, thus indicating that these two materials can be distinguished by LIBS. 
Also visible, however, are those data points that lie outside the $95 \%$ confidence internal. These still show clear separation between uncompressed charcoal and graphite.

295

296

297

298

300

301

302

303

304

305

306

307

308

309

310

311

312

313

314

The loadings [59] for each PC relate to the contributions that each spectrometer channel makes to the overall principal component for an analysis. Loadings allowed the relative importance of peaks present in the spectra in terms of their ability to discriminate between materials to be studied, thus highlighting some of the key elements that the discrimination between materials was actually based on.

An examination of the loadings for the first three PC's provides an indication of the elements they represent. Figure 7, which also shows an example reference spectrum, shows the relative importance of the peaks outlined in Table 3 in terms of their ability to separate graphite and uncompressed charcoal. PCs 1 to 3 all have high loading values between $750-850 \mathrm{~nm}$ that reflects emissions from atomic and molecular nitrogen and oxygen in air. As they occur in all three principal components, these do not support differentiation between graphite and charcoal.

Loadings in PC1 emphasise the different background levels in the six spectrometers used in the LIBS experimental setup. This instrumentation-related factor also does not appear to support distinguishing between the samples. However these features could be removed, using post-processing algorithms, to improve the sensitivity of the technique. The loadings for the first PC also contain the classic $\mathrm{Na}$ doublet at $588.98 \mathrm{~nm}$ and $589.54 \mathrm{~nm}$, several atomic calcium emission lines e.g. at $480 \mathrm{~nm}$ and $559 \mathrm{~nm}$. As expected, these lines are found with much greater intensity in charcoal and reflect the composition of charcoal as described earlier, suggesting a possible reason for the confidence ellipse separation in PCA.

However, as Figure 7 shows, loadings for the second and third PC's include: (i) spectral lines between $240-450 \mathrm{~nm}$, (ii) two sets of readily identifiable lines corresponding to molecular emissions from carbon $\left(\mathrm{C}_{2}\right)$ clusters [52] - one with the head of the Swan system (0-0) group of transitions at $516 \mathrm{~nm}$; and the other with the head of the Swan system (0-2) group of transitions at $619 \mathrm{~nm}$. Additionally, carbon atomic emission lines are observed at $407 \mathrm{~nm}$ and 588-89 nm. Finally, visible within PC3 are the distinctive molecular emissions from CN species within the violet $(0,0)$ series are visible, with the head at $388.3 \mathrm{~nm}$. 
During PCA analysis and examination of the loadings, differences were noted in the intensities of the molecular emission lines from $\mathrm{C}_{2}$ and $\mathrm{CN}$ under the same conditions. It was postulated that these may provide a key factor in differentiating graphite and uncompressed charcoal below $100 \mathrm{~mJ}$, and it was decided to perform further examination of these features.

It is known that the formation of these free radicals and the intensity of their emissions can vary as a function of both pulse energy and delay time [60][61], so understanding why the spectral emissions from atomic carbon and $\mathrm{C}_{2}$ and $\mathrm{CN}$ molecular species change as a function of delay time and pulse energy will support identification of LIBS settings that enable optimal separation of these carbon-rich materials.

Figure 7 Plot of PCA loadings for PCA3 (top), PCA2 (2nd), PCA 1 (3rd) and a uncompressed charcoal sample reference spectrum (100 $\mathrm{mJ}$ pulse energy with $1.28 \mu$ s delay time).

The ultimate aim of this research area is to enable the deployment of LIBS for routine sorting and screening of radioactive wastes. To reach that point all analysis equipment artefacts as shown in PC1 and PC2 in Figure 7 would have to be eliminated so the only significant variations measured by routine LIBS analysis will be due to the material type, as shown in PC3.

\subsection{Multivariate analysis - Hierarchical Cluster Analysis (HCA)} examined using Hierarchical Cluster Analysis (HCA). As with PCA, this is an unsupervised method that in this case classifies data into clusters depending upon its similarity. A dendrogram (tree diagram) was created using Ward's method [62]. This classifies all of the measurements used in the study, where, mathematically, the separation between data values is calculated by their Euclidean distances. The clusters selected are therefore those that were generated with minimum variance in their Euclidean distances from groups selected by random sampling.

Figure 8 shows the HCA dendrogram analysis. The highest level data from this study are clearly located into two clusters representing graphite $(\mathrm{g})$ and charcoal $(\mathrm{C})$ at laser pulse energies of 10,50 , and $90 \mathrm{~mJ}$, whilst data for graphite and charcoal at $100 \mathrm{~mJ}$ occur across both groups. Overall the dendrogram indicates that differentiation of charcoal and graphite appears to be possible at $>/=10 \mathrm{~mJ}$ 
predominantly results at $100 \mathrm{~mJ}$ ns laser pulse energies, a small number of other data (at 50 and $90 \mathrm{~mJ}$ but none at $10 \mathrm{~mJ}$ ) were also identified, suggesting that although the overall picture is one of differentiation, it does not appear to be unequivocal at 50 and $90 \mathrm{~mJ}$, and some other supporting evidence to further enhance the differentiation would be useful.. The causes of this change in behaviour are likely to be caused by fragmentation processes occurring in the LIBS plasma and are discussed below.

Figure 8 Hierarchical cluster analysis (HCA), utilising the principal component analysis scores (laser energy colour code is same as Figure 5). Note the segregation of graphite (g) and uncompressed carbon (c), and the overlap due to no segregation at $100 \mathrm{~mJ}$

\subsection{Analysis of molecular emissions}

The above analysis suggests that discrimination could be based on two features: (i) the presence of $\mathrm{CN}$ molecular lines in charcoal samples, and (ii) the presence of molecular $\mathrm{C}_{2}$ Swan system lines in graphite samples. Analysis of the molecular emissions was undertaken on crushed compressed charcoal to confirm this, to ascertain optimal laser pulse energies (and in particular to address the lack of discrimination at $100 \mathrm{~mJ}$ ), and to note any effect of varying delay times. This also enabled examination of the mechanism of formation of $\mathrm{CN}$ emissions [57][58][62].

$\mathrm{C}_{2}$ molecular emission lines can form by direct ablation of clusters of carbon fragments, or through recombination of $\mathrm{C}$ atoms post-ablation [50][63][64][65]. Nitrogen in the $\mathrm{CN}$ groups could be formed directly from $\mathrm{N}$ and $\mathrm{C}$ in the sample as has been shown for $\mathrm{N}$ bearing organic molecules [50]. This is unlikely to be the case here as nitrogen is not a chemically bound constituent of either material. If an impurity then this was below the limit of detection for the XRF analysis. However, $\mathrm{CN}$ can also be generated by the reaction of $C$ atoms with nitrogen in air; either by ionised $C$ atoms (i.e. $2 \mathrm{C}+\mathrm{N}_{2} \rightarrow$ $2 \mathrm{CN}$ ) or $\mathrm{C}_{2}$ groups reacting with nitrogen (i.e. $\mathrm{C}_{2}+\mathrm{N}_{2}+\mathrm{E}_{\text {kin }}^{\stackrel{k 1}{\mathrm{k} 2}} \underset{\leftarrow}{\stackrel{k 1}{L}} \mathrm{CN}+\mathrm{E}_{\text {kin }}^{\prime}$ [64][66], where $\mathrm{E}_{\text {kin }}$ and $\mathrm{E}_{\text {kin }}$ are respectively the kinetic energies of molecules before and after the reaction). The latter reaction is highly endothermic (with an activation energy of $1.8 \mathrm{eV}$ [68]), and has been shown to require high temperatures of the type that occur in the shockwave generated during initial plasma formation [63]. 
Figure 9 A shows the variation with 25, 50, and $100 \mathrm{~mJ}$ pulse energies of the $\mathrm{CN}$ violet series at $388.3 \mathrm{~nm}$ for graphite (i) and compressed charcoal (ii). Graphite shows a distinctive set of peaks at all pulse energies, but these peaks only formed at $100 \mathrm{~mJ}$ in charcoal. XRF analysis of the charcoal confirmed that significant nitrogen was not present in charcoal (Table 2); therefore CN could only be produced by the interaction of either $\mathrm{C}_{2}$ or atomic carbon with atmospheric nitrogen. From the latter experiments, it can be concluded that $\mathrm{CN}$ formation takes place at least up to $50 \mathrm{~mJ}$ and does not happen at $100 \mathrm{~mJ}$. Only the data obtained at $10 \mathrm{~mJ}$ have no data in the overlap zone.

Therefore, since the formation of $\mathrm{CN}$ spectral lines was a significant statistical contributor to the differentiation between crushed compressed charcoal and graphite, discrimination of the two materials using these features was deemed only possible up to $50 \mathrm{~mJ}$ pulse energy from the data presented.

With a fixed delay time of $1.28 \mu \mathrm{s}$, the $C_{2}$ Swan series, with a head peak at $516 \mathrm{~nm}$, was observed at all pulse energies for graphite, with a major increase in intensity at $100 \mathrm{~mJ}$ (Figure $9 \mathrm{~B}(\mathrm{i})$ ), but was difficult to distinguish above background for crushed compressed charcoal, with only the head peak being clearly discernible at $516 \mathrm{~nm}$ (Figure $10 \mathrm{~B}(\mathrm{ii})$ ). It is possible that adjacent stronger intensity peaks, belonging mainly to calcium in the charcoal (e.g. $\mathrm{Ca}(\mathrm{III})$ at $513 \mathrm{~nm}$ and $\mathrm{Ca}(\mathrm{I})$ at $518.8 \mathrm{~nm}$ ), may hide the weaker $\mathrm{C}_{2}$ peaks. However it is also possible that Swan series emissions are low intensity because very small amounts of $\mathrm{C}_{2}$ clusters are present below a laser pulse energy of $100 \mathrm{~mJ}$.

Figure 9 (A) CN violet system spectral lines (head line at $388.3 \mathrm{~nm}$ ) for crushed compressed charcoal and graphite; (B) $C_{2}$ Swan series (head at $516 \mathrm{~nm}$ ) for charcoal and graphite. All at $1.28 \mu$ selay time and 25 , 50 and $100 \mathrm{~mJ}$ pulse energies In summary, at $1.28 \mu \mathrm{s}$, (i) $\mathrm{CN}$ violet series peaks (with the head peak at $388.3 \mathrm{~nm}$ ) can be identified in LIBS spectra for graphite at all 3 laser pulse energies used, but are only present in the LIBS spectrum for crushed compressed charcoal at $100 \mathrm{~mJ}$; and (ii), $\mathrm{C}_{2}$ Swan Series peaks (with the head peak at $516 \mathrm{~nm}$ ) can be identified in LIBS spectra for graphite at all laser pulse energies but not in LIBS spectra for charcoal (although the head peak is visible at $516 \mathrm{~nm}$ at $100 \mathrm{~mJ}$ laser pulse energy). Thus, LIBS discrimination was achieved, utilising the molecular $\mathrm{CN}$ violet and $\mathrm{C}_{2}$ Swan series of peaks within LIBS spectra for graphite and charcoal, at ns laser pulse energies up to $50 \mathrm{~mJ}$. 
Table 4 Summary of molecular emission analysis results for graphite and crushed compressed charcoal at various laser pulse energies (delay time $1.28 \mu \mathrm{s}$ )

The same $\mathrm{C}_{2}$ Swan series spectral lines were investigated as a function of delay time (but with a fixed pulse energy of $50 \mathrm{~mJ}$ ) to assess any impact on the discrimination noted above. Figure $10(\mathrm{~A})$ shows that Swan series lines are prominent in graphite, even at short delay times. The high intensities, observed at short delay times, are indicative of the ablation of $\mathrm{C}_{2}$ clusters from graphite surfaces [53][62]. For charcoal, a different relationship was observed: peak intensities were significantly higher after $3 \mu \mathrm{s}$, with almost no signal at shorter delays. This is suggestive of an alternative mechanism whereby carbon atoms recombine to form $\mathrm{C}_{2}$ or larger carbon clusters formed during laser ablation then dissociate to $\mathrm{C}_{2}$ later in the plasma. In that process, higher $\mathrm{C}_{2}$ emission intensities are generated at longer delay times due to the formation of $\mathrm{C}_{2}$ clusters as the plasma cools. crushed compressed charcoal (all at $50 \mathrm{~mJ}$ laser pulse energy)

424 In summary, between 1 and $3 \mu$ s the $C_{2}$ Swan series peaks are prominent in graphite spectra, but not in spectra for charcoal, whereas between 3 and $15 \mu \mathrm{s}$, the opposite is true. This highlights that whilst discrimination, based on the $\mathrm{C}_{2}$ Swan series peaks, was successfully achieved at a delay time of $1.28 \mu \mathrm{s}$, the ability to discriminate at other delay times may vary.

\subsection{Discrimination using atomic carbon lines} lines for atomic carbon. Lines for the molecular species could be resolved on graphite LIBS spectra, alongside lines for atomic C - represented for example, by the $247 \mathrm{~nm}$ line, which could be identified at all laser pulse energies and delay times (Figure $11 \mathrm{~A}$ and $\mathrm{B}$ ). The same $\mathrm{C}$ line could not be resolved in any situation for charcoal (same figure). The presence of an atomic $\mathrm{C}$ line in LIBS graphite spectra and corresponding lack of the same line in LIBS charcoal spectra potentially allows an extra discriminatory feature between the two materials. This is perhaps not surprising considering the relatively high thermal conductivity of graphite compared to that of charcoal, which has a thermal conductivity that is an order of magnitude lower, and its relatively low vaporisation point. 
Interestingly, this finding also indicates a lack of atomic carbon in the plasma for charcoal, where it is

439 present in the graphite plasma, suggesting charcoal ablation releases $C_{2}$ molecular fragments,

440 whereas graphite ablation releases both molecular $\mathrm{C}_{2}$ and atomic $\mathrm{C}$.

441 The lack of atomic $\mathrm{C}$, the presence of molecular $\mathrm{C}_{2}$ in the crushed compressed charcoal plasma, and assuming $\mathrm{CN}$ is only formed at $100 \mathrm{~mJ}$ in charcoal (as per this study), also suggests that the $\mathrm{CN}$ is formed by reaction of atmospheric nitrogen with $\mathrm{C}_{2}$ molecular fragments [69]. It was not possible, using these results, to suggest the reason for the presence of $\mathrm{CN}$ peaks in graphite spectra (for example, it may be due to the differing thermal properties for each material). However, further investigation is outside the scope of this paper. materials using LIBS and stand-off LIBS.

Here we propose a new workflow to enable the speedy characterisation of graphite, graphite bearing and miscellaneous C-bearing materials using LIBS and stand-off LIBS. 2D and 3D analysis of spectra obtained from single-shot rastering across each sample illustrated the compositional variation within each material, and whilst some peak identification was possible, particularly of the various carbon species, it did not lead to a decisive fingerprint for each material.

PCA provided a good discrimination between the two materials, based on differences in principal components. HCA supported this, and both together provided an indication that discrimination at up to $50 \mathrm{~mJ}$ ns laser pulse energy was possible. Examination of PC loadings further endorsed this, and suggested that the PCs comprised a combination of impurities (e.g. Na \& $\mathrm{Ca}$ ) and atomic and molecular carbon species, created during the LIBS process; but with differing features depending on the material. Molecular isotopic analysis further investigated these features, and identified molecular carbon species formed during LIBS of graphite that were not formed during LIBS of crushed compressed charcoal (apart from at $100 \mathrm{~mJ}$ ), including $\mathrm{CN}$ and $\mathrm{C}_{2}$ species. Additionally, it was noted 
crushed compressed charcoal, suggesting another discriminatory feature. Experimentally, the above findings suggest that optimal conditions for LIBS discrimination of graphite and charcoal include a ns laser pulse energy lower than $90 \mathrm{~mJ}$ and a laser delay time of $1.28 \mu \mathrm{s}$. Distinction between graphite and other carbonaceous materials analysis is certainly possible, using $C$ peaks; and the analysis can be undertaken in ambient air.

Findings in published literature support the postulate that $C$ within mixed graphite-bearing wastes can indeed be used as a discriminator[51][67][70][71][72][73][74], whilst several authors report the use of PCA for discrimination of complex materials (e.g. [75]). It is noted that many other multivariate methods could also have been used that also allow systematic investigation of a very large number of variables such as SIMCA (soft independent modelling of class analogues and neutral networks). There is no assumption that PCA is more or less appropriate than these methods; it is simply noted that it in this case the method provided the required information to allow for material discrimination [59].

From this study a new workflow has been developed to enable rapid discrimination analysis of graphite and C-bearing wastes (Figure 12 A and B) comprising: (A) Optimal LIBS set up and (B) the analysis workflow itself. The latter comprises: (1) Visual analysis of spectra and peak identification; (2) Multivariate analysis of the whole spectral broadband utilising all the results, including (2a) bootstrapping, (2b) PCA, (2c) HCA, (2d) loadings analysis; and (3) molecular isotopic analysis of C species.

Figure 12 Fingerprint-based workflow for the characterisation of graphite and graphite-bearing materials during nuclear decommissioning

\section{CONCLUSIONS} analysis and molecular emission spectroscopy of $\mathrm{C}$ species resulting from the LIBS process, can be used to discriminate easily between graphite and other materials with high elemental $\mathrm{C}$ content in ambient air. The new workflow is suitable for discrimination of nuclear grade graphite and other Cbearing wastes during nuclear decommissioning and waste management of graphite wastes. Having demonstrated this utility for the test case of different $C$ based materials, future work will extend the evaluation to other typical decommissioning materials. 
For graphite and both compressed and uncompressed charcoal the primary $\mathrm{C}$ peaks (including those of new species created during the LIBS process), and some impurity peaks can be easily identified

500 through visual inspection of 2D and 3D spectra. Yet, the latter also serves to highlight the immense difficulties associated with discriminating between the two materials.

However, multivariate analysis comprising bootstrapping, PCA, HCA and examination of loadings was used to successfully discriminate between PGA graphite and other C-bearing materials (in this case compressed and uncompressed lumpwood charcoal). This was based on PCs present in the LIBS plasma, including atomic and molecular C species formed during the LIBS process. Analysis of the spectral lines, produced by the latter, identified the presence of lines for the $\mathrm{CN}$ (violet) and $\mathrm{C}_{2}$ Swan series within the spectra for graphite, but not for charcoal.

Multivariate analysis also showed that a ns laser pulse energy higher than $90 \mathrm{~mJ}$ was not suitable for gathering appropriate data, but all the above findings suggest that an inexpensive commercially available in-situ LIBS set up, using standard Czerny-Turner spectrometers, a laser pulse energy no higher than $90 \mathrm{~mJ}$, and a fixed laser pulse delay of $1.28 \mu \mathrm{s}$, could be used to discriminate between nuclear grade graphites and other C-bearing materials.

513 Further optimisation of data processing is possible that could support progressing from the current research based equipment into an automated monitoring tool that can be utilised to screen high $\mathrm{C}$ content wastes. For instance a statistically supervised method, such as partial least squaresdiscriminant analysis (PLS-DA), can be used to calibrate an automated LIBS based screening process [76].

\section{ACKNOWLEDGEMENTS}

519 This study acknowledges funding from National Nuclear Laboratory Waste Management and

520 Decommissioning Characterisation Innovation, Research \& Development Programme, and the Centre

521 for Innovative Nuclear Decommissioning and Engineering (CINDe) Programmes, the University of Manchester, the EPSRC, and the Royal Society Industry Fellowship. 
524 [1] Wareing, A., Abrahamsen-Mills, L., Fowler, L., Grave, M., Jarvis, R., Metcalfe, M., Norris, S., and Banford, A. Development of integrated waste management options for irradiated graphite. Nuclear Engineering and Technology, 2017 (in press).

[2] Banford, A., Eccles, H., Graves, M. J., Von Lensa, W., and Norris, S., CARBOWASTE - An Integrated Approach to Irradiated Graphite. Nuclear Future, 2008, 4 (5): pp. 268-270.

[3] Metcalfe, M. P., Banford, A. W., Eccles, H., and Norris, S. EU Carbowaste project: Development of a toolbox for graphite waste management. Journal of Nuclear Materials, 436(1), 2013, pp.158-166.

[4] Von Lensa, W., Vulpius, D., Steinmetz, H. J., Girke, N., Bosbach, D., Thomauske, B., Banford, A. W., Bradbury, D., Grave, M. J., Jones, A. N. and Grambow, B., 2011. Treatment and disposal of irradiated graphite and other carbonaceous waste. ATW-Internationale Zeitschrift fur Kernenergie, 56(4), 2011, pp 263.

[5] Mills, R. W., Riaz, Z., and Banford, A. W. Nuclear data issues in the calculation of C-14 and Cl-36 in irradiated graphite. In Proceedings of the European Nuclear Conference (ENC'12), 2012.

[6] Metcalfe, M. P., and Mills, R. W. Radiocarbon mass balance for a Magnox nuclear power station. Annals of Nuclear Energy, 2015, vol. 75: pp 665-671.

[7] White, I.F., et al., Assessment of Graphite management modes for graphite form reactor decommissioning, in CEC, E. Commission, Editor. 1984.

[8] Smith, S. W., and Bredell. P. J. Development of a strategy for the management of PBMR spent fuel in South Africa. Nuclear Engineering Design, 2010, vol. 240: pp 2415-2420.

[9] Wallbridge, S., Banford, A., and Azapagic, A. Life cycle environmental impacts of decommissioning Magnox nuclear power plants in the UK. International Journal of Life Cycle Assessment. 2013. 18.5. pp 990-1008.

[10] Samseth, J., Banford, A., Batandjieva-Metcalf, B., Cantone, M. C., Lietava, P., Peimani, H., and Szilagyi, A. Closing and Decommissioning Nuclear Power Reactors. UNEP Year book, 2012, $35-49$.

[11]Khater, M. A. Laser-induced breakdown spectroscopy for light elements detection in steel: State of the art. Spectrochimica Acta Part B: Atomic Spectroscopy, 2013, vol. 81: pp 1-10.

[12] Cremers D, and Radzemski L. Handbook of Laser Induced Breakdown Spectroscopy, John Wiley and Sons Ltd., New York, 2006. 
[13]Miziolek, A. W., Palleschi, V., and Schrchter, I. Laser induced breakdown spectroscopy (LIBS), Cambridge University. 2006.

[14]Noll, R. Laser-induced breakdown spectroscopy: fundamentals and applications, Springer-Verlag, Berlin, 2012.

[15] Singh, J. P., and Thakur, S. N. Laser induced breakdown spectroscopy, Elsevier, Oxford, 2007.

[16] St-Onge L., Kwong, E., Sabsabi, M., and Vados, E. B. Quantitative analysis of pharmaceutical products by laser-induced breakdown spectroscopy. Spectrochimica Acta Part B, 2002, vol. 57: pp $1131-1140$.

[17] Mowery, M., Sing, R., Kirsch, J., Razaghi, A., Béchard, S., and Reed, R. Rapid at-line analysis of coating thickness and uniformity on tablets using laser induced breakdown spectroscopy. Journal of Pharmaceutical and Biomedical Analysis, 2002; vol. 28: pp 935-43.

[18] Wiens, R. C., Arvidson, R. E., Cremers, D. A., Ferris, M. J., Blacic, J. D., Seelos, I. V. F. P., and Deal K. S. Combined remote mineralogical and elemental identification from rovers: field and laboratory tests using reflectance and laser-induced breakdown spectroscopy, Journal of Geophysical Research, 2002, vol. 107: pp 3.01-3.14.

[19] Sallé, B., Cremers, D., Maurice, S., Wiens, R., and Fischet, P. Evaluation of compact spectrograph for in-situ and stand-off Laser-Induced Breakdown Spectroscopy analyses of geological samples on Mars missions. Spectrochimica Acta Part B, 2005, vol. 60: pp 805-10.

[20] Subedi, K., Trejos, T., and Almirall, J., Forensic analysis of printing inks using tandem Laser Induced Breakdown Spectroscopy and Laser Ablation Inductively Coupled Plasma Mass Spectrometry. Spectrochimica Acta Part B, 2015, vol. 103-104: pp 76-83.

[21]Guirado, S., Fortes, F., and Laserna, J. Elemental analysis of materials in an underwater archaeological shipwreck using a novel remote laser-induced breakdown spectroscopy system. Talanta, 2015, vol. 137: pp 182-8.

[22] Santos, Jr D., Nunes, L, Trevizan, L., Godoi, Q., Leme, F., and Braga, J. Evaluation of laser induced breakdown spectroscopy for cadmium determination in soils, Spectrochimica Acta Part B, 2009, vol. 64: pp 1073-8.

[23] Mansoori, A., Roshanzadeh, Khalaji, M., and Tavassoli S. Quantitative analysis of cement powder by laser induced breakdown spectroscopy. Optics and Lasers in Engineering, 2011, vol. 49: pp 318-23. 
[24]Alamelu, D., Sarkar, A., and Aggrawal, S. Laser-induced breakdown spectroscopy for simultaneous detection of Sm, Eu and Gd in aqueous solution. Talanta, 2008, vol. 77: pp 256-61.

[25] McNaghten, E. D., Parkes, A. M., Griffiths, B. C., Whitehouse, A. I., and Palanco, S. Detection of trace concentrations of helium and argon in gas mixtures by laser-induced breakdown spectroscopy. Spectrochimica Acta Part B, 2009, vol. 64: pp 1111-1118.

[26] Syred, C., Griffiths, A. J., Syred, N., Beedie, D., and James, D. A clean, efficient system for producing Charcoal, Heat and Power (CHaP). Fuel, 2006, vol. 85: pp 1566-1578.

[27]De Giacomo, A., Dell'Aglio, M., Gaudiuso, R., Santagata, A., Senesi, G. S., Rossi, M. A Laser Induced Breakdown Spectroscopy application based on Local Thermodynamic Equilibrium assumption for the elemental analysis of alexandrite gemstone and copper-based alloys. Chemical Physics, 2012, vol. 398: pp 233-238.

[28] Kramida, A., Ralchenko, Yu., Reader, J. and NIST ASD Team (2018). NIST Atomic Spectra Database (version 5.5.6), [Online]. Available: https://physics.nist.gov/asd [April 06 2018]. National Institute of Standards and Technology, Gaithersburg, MD.

[29]Barefield, II. J., Judge, E., Berg, J., Wilson, S., Le, L., and Lopez, L., Analysis and Spectral Assignments of mixed actinide oxide samples using laser induced breakdown spectroscopy (LIBS), Applied Spectroscopy, 2013, vol. 67: pp 433-40.

[30] Jung, E., Lee, D., Yun, J., Kim, J., Yeon, J., and Song, K. Quantitative determination of U and Eu in glass matrix by laser induced breakdown spectroscopy. Spectrochimica Acta Part B, 2011, vol. 66: pp 761-764.

[31]Williams, A, and Phongikaroon, S. Laser-Induced Breakdown Spectroscopy (LIBS) in a Novel Molten Salt Aerosol System. Applied Spectroscopy, 2016, vol. 0: pp 1-6.

[32] Madhavi, Z., Allman, M. S., Brice, D. J., Martin, R. C., and Andre, N. O. Exploring laser-induced breakdown spectroscopy for nuclear materials analysis and in-situ applications. Spectrochimica Acta Part B, 2012, vol. 74-75: pp 177-183.

[33] Sarkar, A., Telmore, V. M., Alamelu, D., and Aggarwal, S. K. Laser induced breakdown spectroscopic quantification of platinum group metals in simulated high level nuclear waste. Journal of Analytical Atomic Spectrometry, 2009, vol. 24: pp 1545-1550.

[34]Chan, G. C. Y, Mao, X., Choi, I., Sarkar, A., Lama, O. P., Shuh, D. K., Russo, R. E. Multiple 
emission line analysis for improved isotopic determination of uranium - a computer simulation study. Spectrochimica Acta Part B, 2013, vol. 89: pp 40-49.

[35]Wang, X., Motto-Ros, V., Panczer, G., De Ligny, D., Yu, J., Benoit, J. M., Dussossoy, J. L., and Peuget, S. Mapping of rare earth elements in nuclear waste glass-ceramic using micro laser-induced breakdown spectroscopy. Spectrochimica Acta Part B, 2013, vol. 87: pp 139-146.

[36] Lang, A., Engelberg, D., Smith, N. T., Trivedi, D., Horsfall, J. P. O., Banford, A., Martin, P. A.,

$$
\text { Coffey, P., Bower, W. R., Walther, C., Weiß, M., Bosco, H., Jenkins, A., and Law, G. T. W. }
$$

$$
\text { Analysis of contaminated nuclear plant steel by laser-induced breakdown spectroscopy, In }
$$
Journal of Hazardous Materials, 2018, vol. 345: pp 114-122.

[37]Whitehouse, A. I., Young, J., Botheroyd, I.M., Lawson, S., Evans, C.P., and Wright ,J. Remote material analysis of nuclear power station steam generator tubes by laser-induced breakdown spectroscopy. Spectrochimica Acta Part B, 2001, vol. 56. pp 821-830.

[38] Whitehouse, A.I. Laser-induced breakdown spectroscopy and its application to the remote characterization of hazardous materials. Spectroscopy Europe, 2006, vol. 18: no 2.

[39] Myakalwar, A. K., Spegazzini, N., Zhang, C., Anubham, S. K., Dasari, R. R., Barman, I., and Gundawar, M. J. Less is more: Avoiding the LIBS dimensionality curse through judicious feature selection for explosive detection. Nature Scientific Reports 5, 2015, article number 12169.

[40]Davies, M.W. Graphite core design in UK reactors. IAEA Report XA9642901. IAEA.

[41] Kratos Analytical. Surface analysis of nuclear graphite. Applications Note MO426. Kratos Analytical, Manchester.

[42] Ancius, D., Ridikas, D., Remeikis, V., Plukis, A., Plukiene, R., and Cometto, M. Evaluation of the activity of irradiated graphite in the Ignalinia Nuclear Power Plant RBMK-1500 reactor. Nucleonika, 2005, 50(3), pp 113-120. Institute of Nuclear Chemistry and Technology, Poland.

[43]White, I. F., Smith, G. G., Saunders, L. J., Kaye, C. J., Martin, T. J., Clarke, G. H., and Wakerley, M. W. Assessment of management modes for graphite from reactor decommissioning. Nuclear Science and Technology, 1984, Report EUR 9232, Directorate-General Science, Research and Development, Commission of the European Communities, ISBN 92-825-4292-0.

[44]Taner, S., Pekey, B., and Pekey, H. Fine particulate matter in the indoor air of barbeque restaurants: Elemental compositions, sources and health risks. Science of the Total Environment, 2013, vol. 454-455: pp 79-87. 
[45] Kabir, E., Kim, K. H., and Yoon, H. O. Trace metal contents in barbeque (BBQ) charcoal products. Journal of Hazardous Materials, 2011, vol. 18: pp 1418-24.

[46] Harilal, S.S., Issac, R. C., Bindhu, C. V., Gopinath, P., Nampoori, V. P. N., and Vallabhan, C. P.

G. Time resolved study of $\mathrm{CN}$ band emission from plasma generated by laser irradiation of graphite. Spectrochimica Acta Part A, 1997, vol. 53: pp 1527-1536.

647

[47] Susaya, J., Kim, K., Ahn, J., Jung, M., and Kang, C. BBQ charcoal combustion as an important source of trace metal exposure to humans. Journal of Hazardous Materials, 2010, vol. 176: pp 932-7.

[48] BSI / ISO. 2016. BS ISO 3310-1:2016: Test sieves. Technical requirements and testing. Test sieves of metal wire cloth. British Standards Institution / International Organization for Standardization.

[49] Applied Photonics Ltd. 2015. LIBSCAN 100 Ultra Modular LIBS System. UM/0168-01/02. Applied Photonics Ltd, Unit 8 Carleton Business Park, Skipton, North Yorkshire BD23 2DE, United Kingdom.

[50] Baudelet, M., Boueri, M., Yu, J., Mao, S. S., Piscitelli, V., Mao, X. L., Russo, R. E. Time-resolved ultraviolet laser-induced breakdown spectroscopy for organic material analysis, Spectrochimica Acta Part B, 2007, vol. 62: pp 1329-1334.

[51] Russo, R. E., Bol'shakov, A. A., Mao, X., McKay, C. P., Perry, D. L., and Sorkhabi, O. Laser Ablation Molecular Isotopic Spectrometry. Spectrochimica Acta Part B, 2011, vol. 66: pp 99-104.

[52] Grégoire, S., Boudinet, M., Pelascini, F., Surma, F., Datelle, V., Holl, Y. 2011. Laser-induced spectroscopy for polymer identification. Annals of Bioanalytical Chemistry, vol. 400: pp 33313340.

[53] Kramida, A., Ralchenko, Y., Reader, J., and NIST ASD Team (2015). NIST Atomic Spectra Database (ver. 5.3), [Online]. Available: http://physics.nist.gov/asd [2016, February 26]. National Institute of Standards and Technology, Gaithersburg, MD. (32 in Smith et al unpublished)

[54]Dinescu, G., Aldea, E., De Giorgi, M. L., Luches, A., Perrone, A., and Zocco, A. Optical emission spectroscopy of molecular species in plasma induced by laser ablation of carbon in nitrogen, Applied Surface Science, 1998, vol. 127-129 (1-2): pp 697-702. 
[55] Chamberlain, B. 2012. Submission of details pursuant to planning permission and variants to construction programme for Sizewell B dry fuel store. Council approval letter, 12.04.09.04/37c 09 October 2012.

[56] Hanson, A. B. (2012). ChemoSpec. An R package for chemometric analysis of spectroscopic and chromatographic data.

[57] R Core Team (2013). R: A language and environment for statistical computing. R Foundation for Statistical Computing, Vienna, Austria. URL http://www.R-project.org/.

[58]Zientek, L. R., and Thompson, B. 2007. Applying the bootstrap to the multivariate case: Bootstrap component/factor analysis Behavior Research Methods, vol. 39 (2): pp. 318-325. Psychonomic Society.

[59]Varmuza, K., and Filzmoser, P. Introduction to Multivariate Statistical Analysis in Chemometrics. CRC Press, Boca Raton, FL, 2009.

[60] Liu, Y., Gigant, L., Baudelet, M., Richardson, M. Correlation between laser-induced breakdown spectroscopy signal and moisture content, Spectrochimica Acta Part B: Atomic Spectroscopy, vol.

$$
\text { 73, 2012, pp 71-74. }
$$

[61] Elnasharty, I. Y., Kassem, A. K., Sabsabi, M., Harith, M. A. Diagnosis of lubricating oil by evaluating cyanide and carbon molecular emission lines in laser induced breakdown spectra, Spectrochimica Acta Part B: Atomic Spectroscopy, vol. 66, Issue 8, 2011, pp 588-593.

[62] Ward, J. H., Jr. Hierarchical Grouping to Optimize an Objective Function. Journal of the American Statistical Association, 1963, vol. 58: pp 236-244.

[63] Ma, Q., and Dagdigian, P. J., Kinetic model of atomic and molecular emissions in laser-induced breakdown spectroscopy of organic compounds, 2011, Annals of Bioanalytical Chemistry, vol. 400(10), pp 3193-3205.

[64] St-Onge, L., Sing, R., Bechard, S., and Sabsabi, M. Carbon emissions following $1.064 \mu \mathrm{m}$ laser ablation of graphite and organic samples in ambient air, 1999, Applied Physics A, vol. 69, S913S916.

[65]Dinescu, G., Aldea, E., De Giorgi, M. L., Luches, A., Perrone, A., and Zocco, A., Optical emission spectroscopy of molecular species in plasma induced by laser ablation of carbon in nitrogen, 1998, Applied Surface Science, vol. 127-129(1-2): pp 697-702. 
[66] Assion, A., Wollenhaupt, M., Haag, L., Mayorov, F., Sarpe-Tudoran, C., Winter, M., Kutschera, U., and Baumert, T. Femtosceond laser-induced breakdown spectroscopy for $\mathrm{Ca}^{2+}$ analysis of biological samples with high spatial resolution. Applied Physics B. Lasers and Optics, 2003, vol. 77: pp 391-397.

[67]McDermott, L. Characterisation and Chemical Treatment of Irradiated UK Graphite Waste. Unpublished PhD Thesis, 2011, University of Manchester.

[68]Dong, M., Lu, J., Yao, S., Zhong, Z., Li, J., Li, J., and Lu, W. Experimental study on the characteristics of molecular emission spectroscopy for the analysis of solid materials containing C and N. Optics Express, 2011, vol. 19, No 18. 17021. Optical Society of America.

[69] Gallimore, S. D., Doctoral Dissertation: A Study of Plasma Ignition Enhancement for Aeroramp Injectors in Supersonic Combustion Applications, Chapter 5: Spectroscopic Studies of Hydrocarbon, Air and Nitrogen Plasmas, 2001, pp 78-95.

[70] Lopez Moreno, C., Palanco, S., Laserna, J. J., DeLucia, F., Miziolek, A. W., Rose, J., Walters, R. A., and Whitehouse, A. I. Journal of Analytical Atomic Spectrometry, 2006, vol. 21: pp 55-60.

[71]DeLucia, F. C., Samuels, A. C., Harmon, R. S., Walters, R. A., McNesby, K. L., LaPointe, A., Winkel, R. J., and Miziolek, A. W. Laser-induced breakdown spectroscopy (LIBS): a promising versatile chemical sensor technology for hazardous material detection. IEEE Sensors Journal, 2005, vol. 5: pp 681-689.

[72] DeLucia, F.C., Harmon, R.S., McNesby, K.L., Winkel, R.J., and Miziolek, A.W. Laser-induced breakdown spectroscopy of energetic materials. Applied Optics, 2003, vol. 42: pp 6148-6152.

[73] Portnov, A., Rosenwaks, S., and Bar, I. Identification of organic compounds in ambient air via characteristic emission following laser ablation. Journal of Luminescence, 2003, vol. 102: pp 408413.

[74]Portnov, A., Rosenwaks, S., and Bar, I. Emission following laser-induced breakdown spectroscopy of organic compounds in ambient air. Applied Optics, 2003, vol. 42: pp 2835-2842.

[75] Madhavi, Z., Allman, M.S., Brice, D.J., Martin, R.C., and Andre, N. O. Exploring laser-induced breakdown spectroscopy for nuclear materials analysis and in-situ applications. Spectrochimica Acta Part B, 2012, vol. 74-75: pp 177-183.

[76]Ye Tian, Zhennan Wang, Xiaoshuang Han, Huaming Hou, Ronger Zheng, Comparative investigation of partial least squares discriminant analysis and support vector machines for 

Acta Part B, 2014, vol. 102: pp 52-57. 
Figure 1
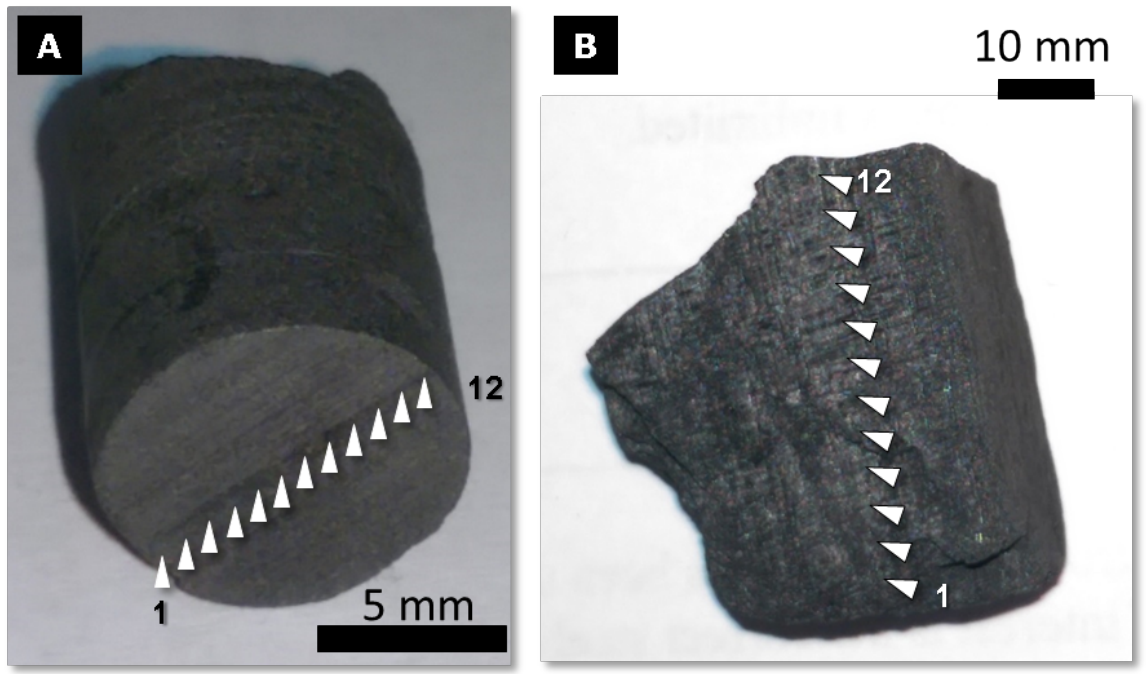

Figure 2

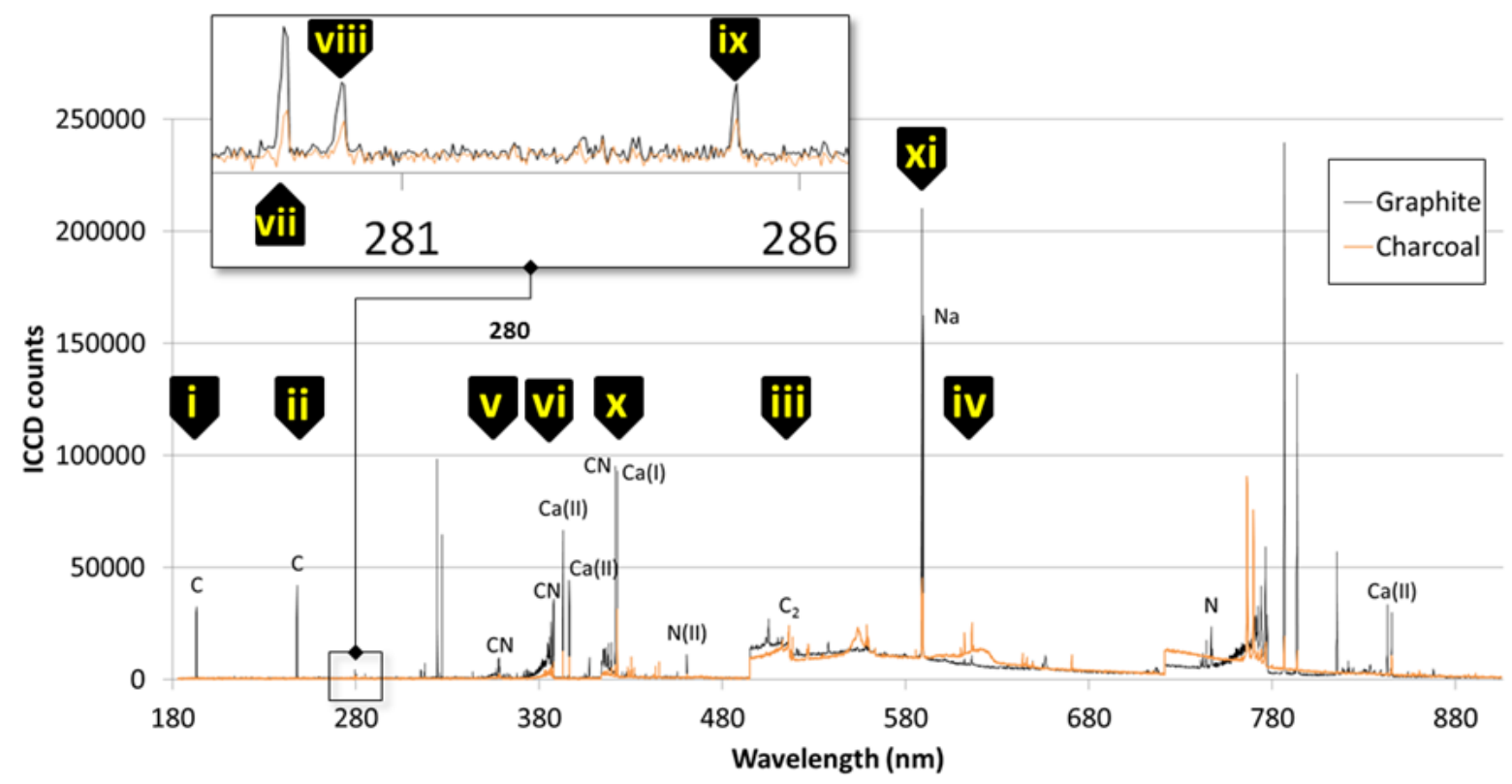

Figure 3 
A $\times 10^{4}$
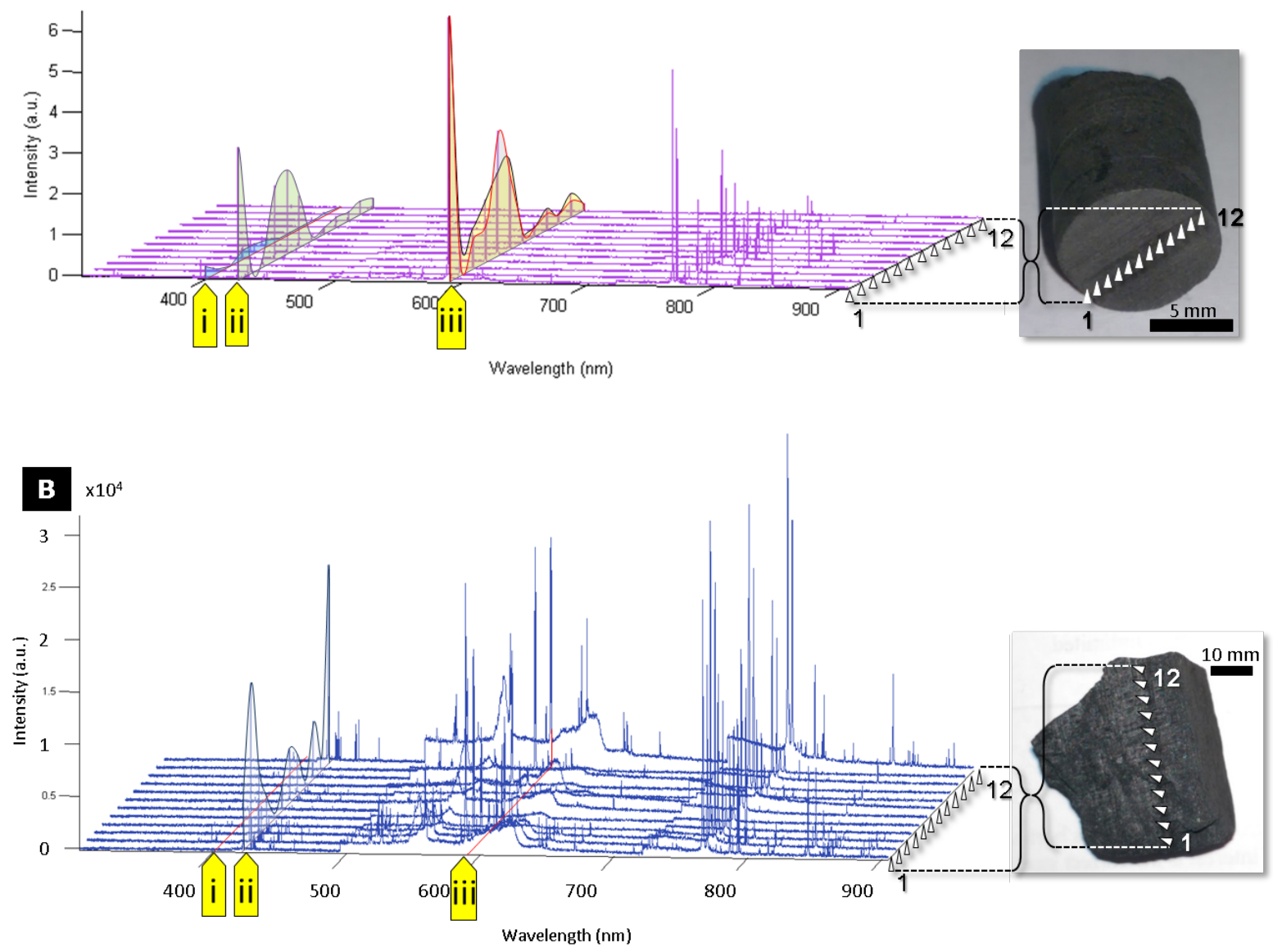

Figure 4

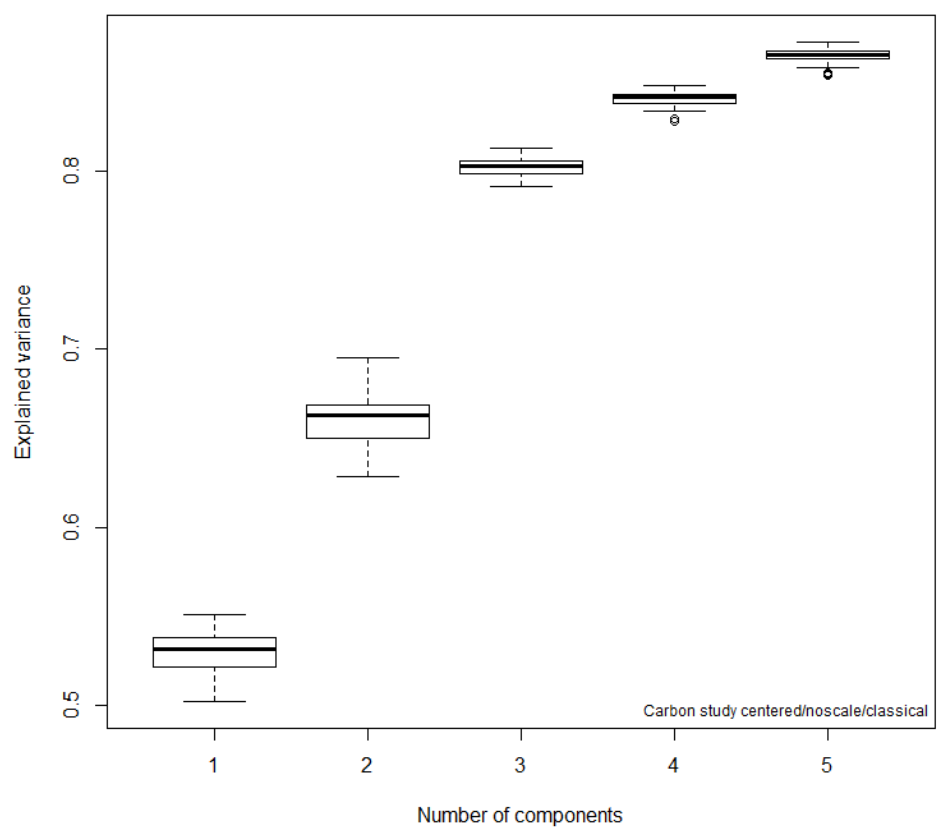


Figure 5

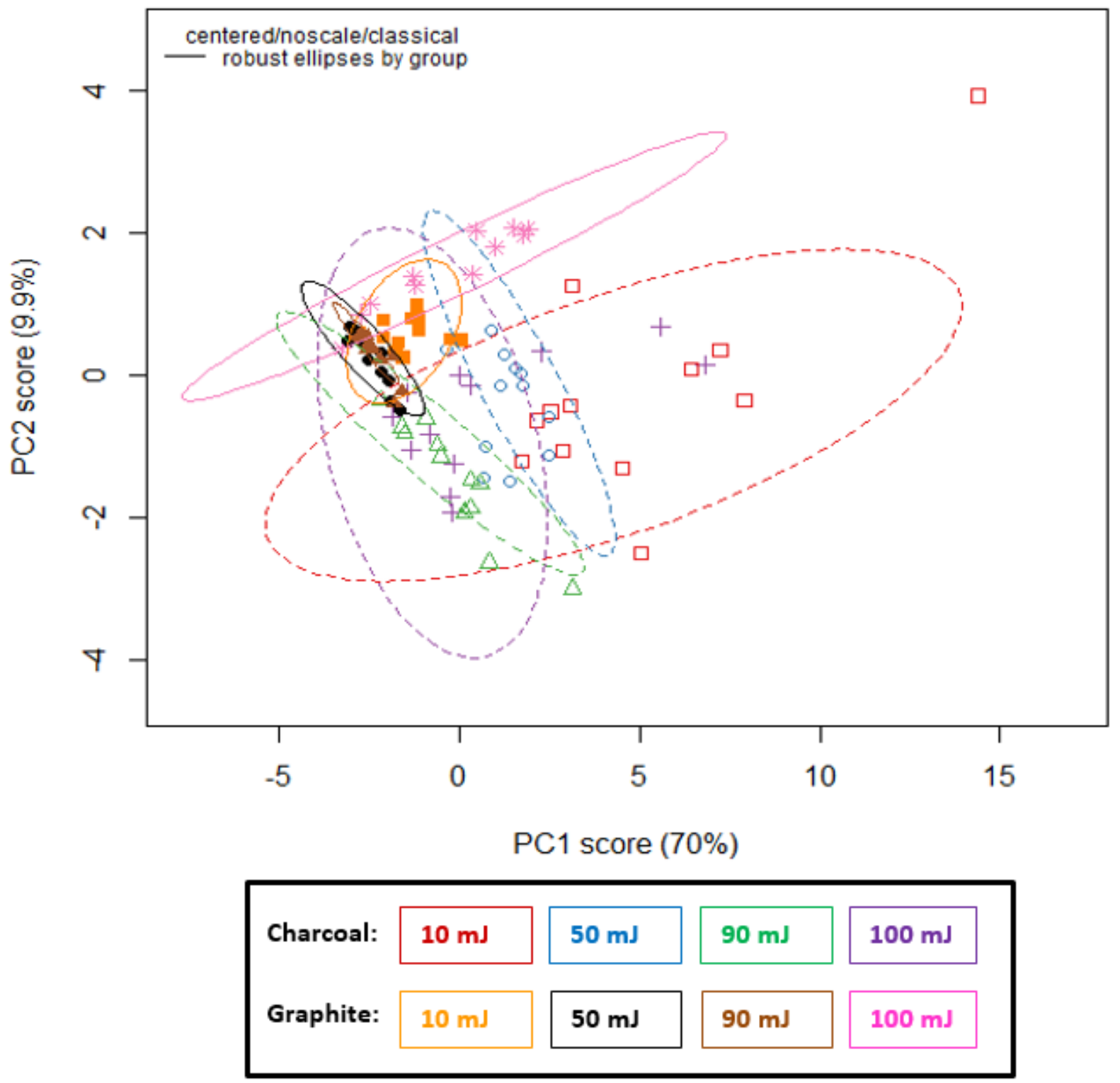

Figure 6 


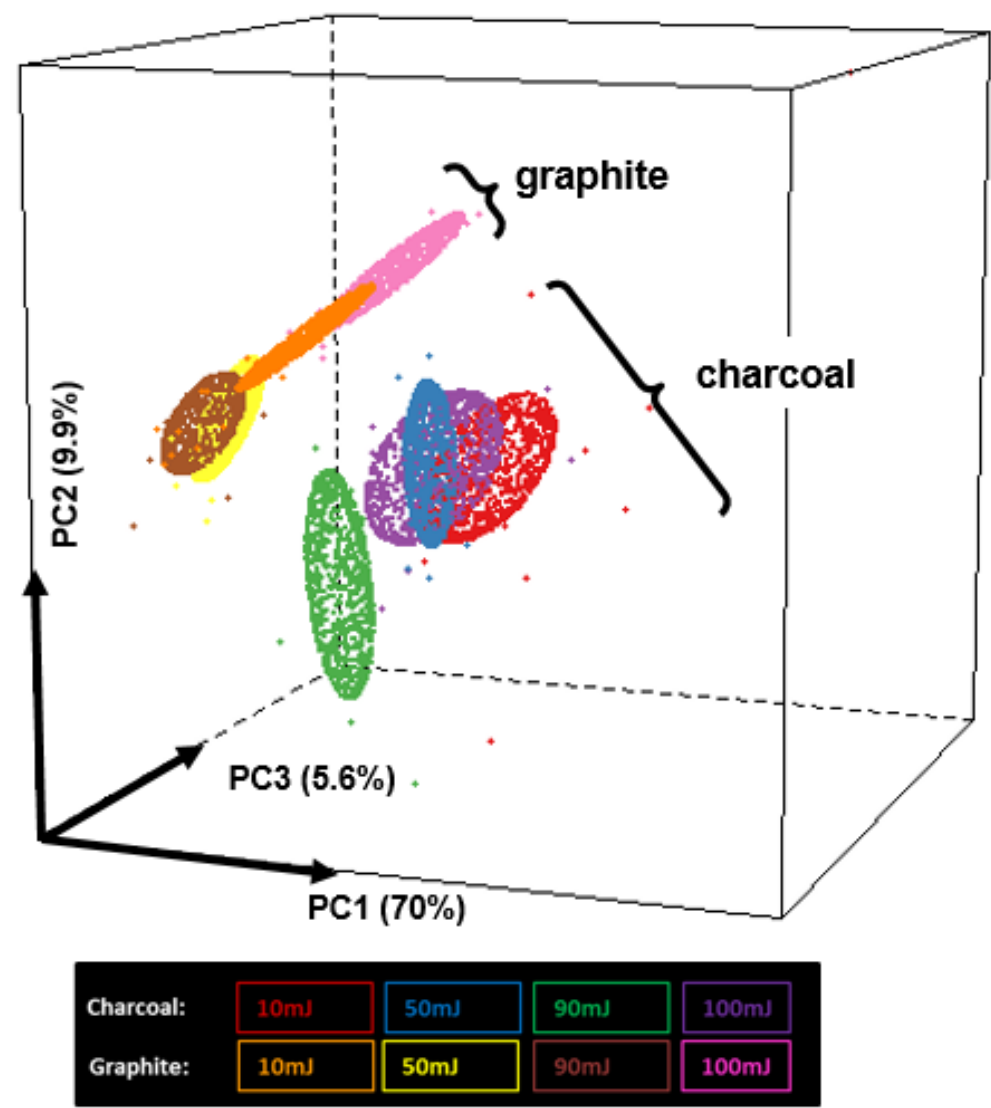

Figure 7 


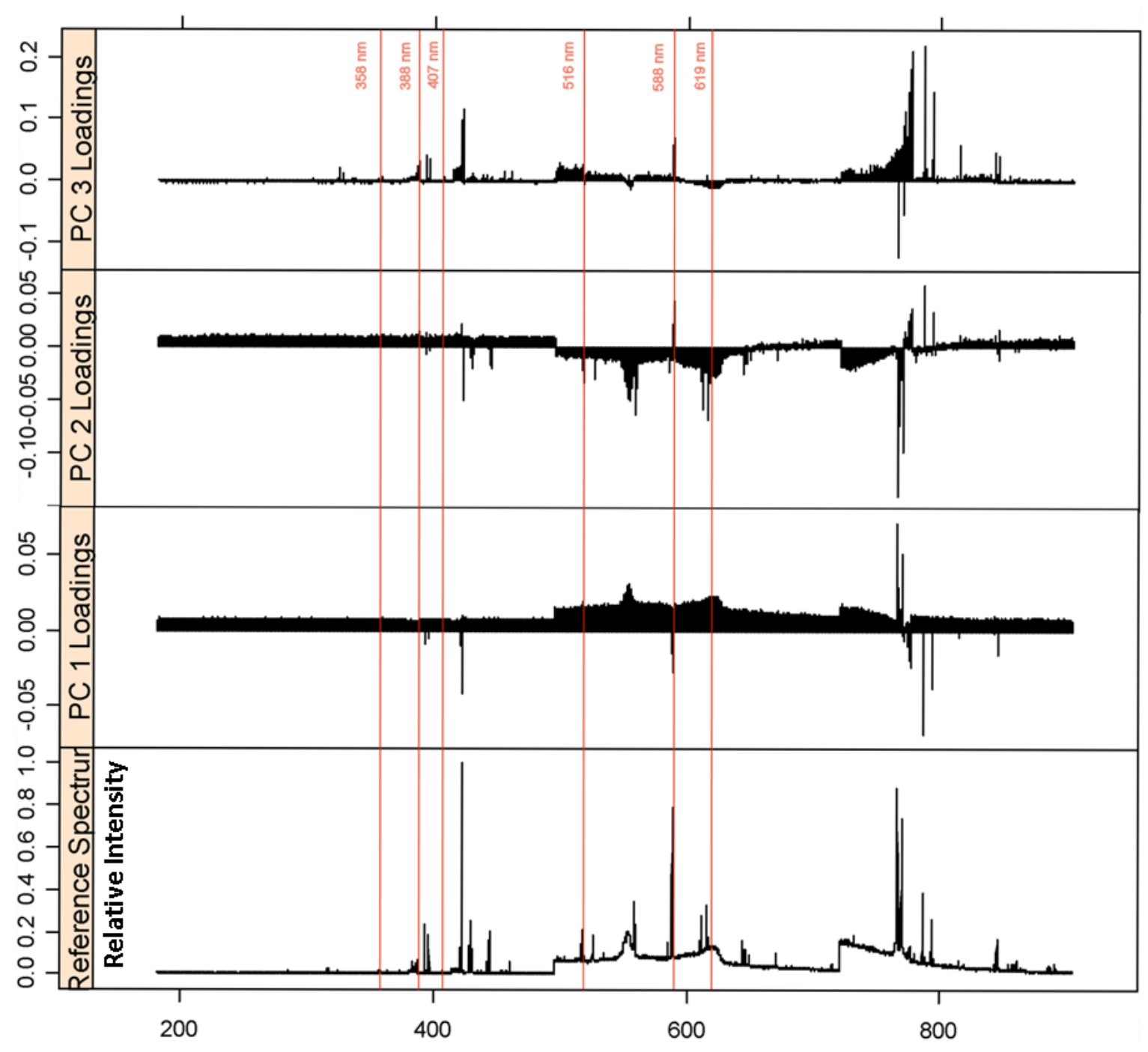

Wavelength $(\mathrm{m})$ centred/nonscale/classical

Figure 8 


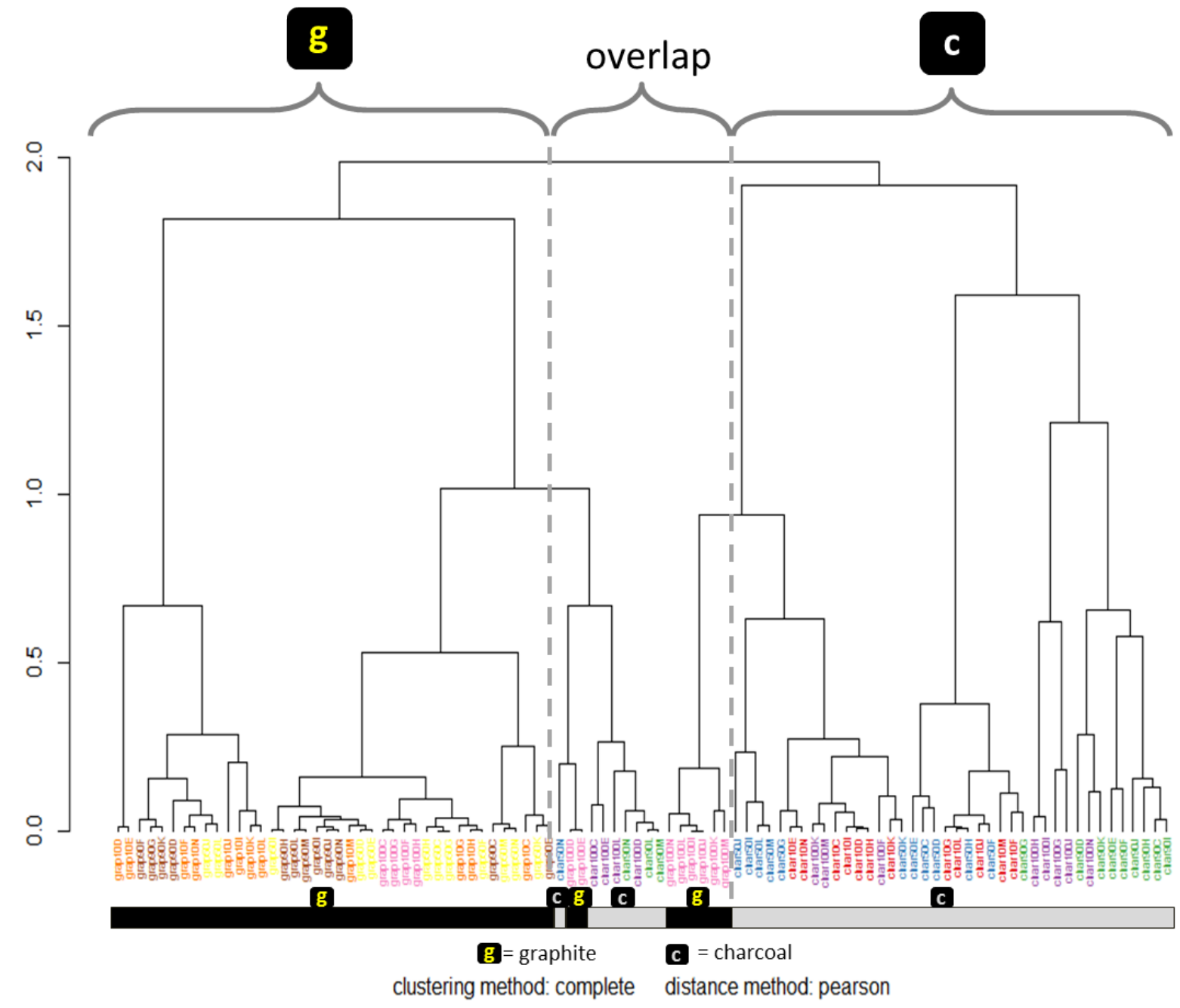

Figure 9 

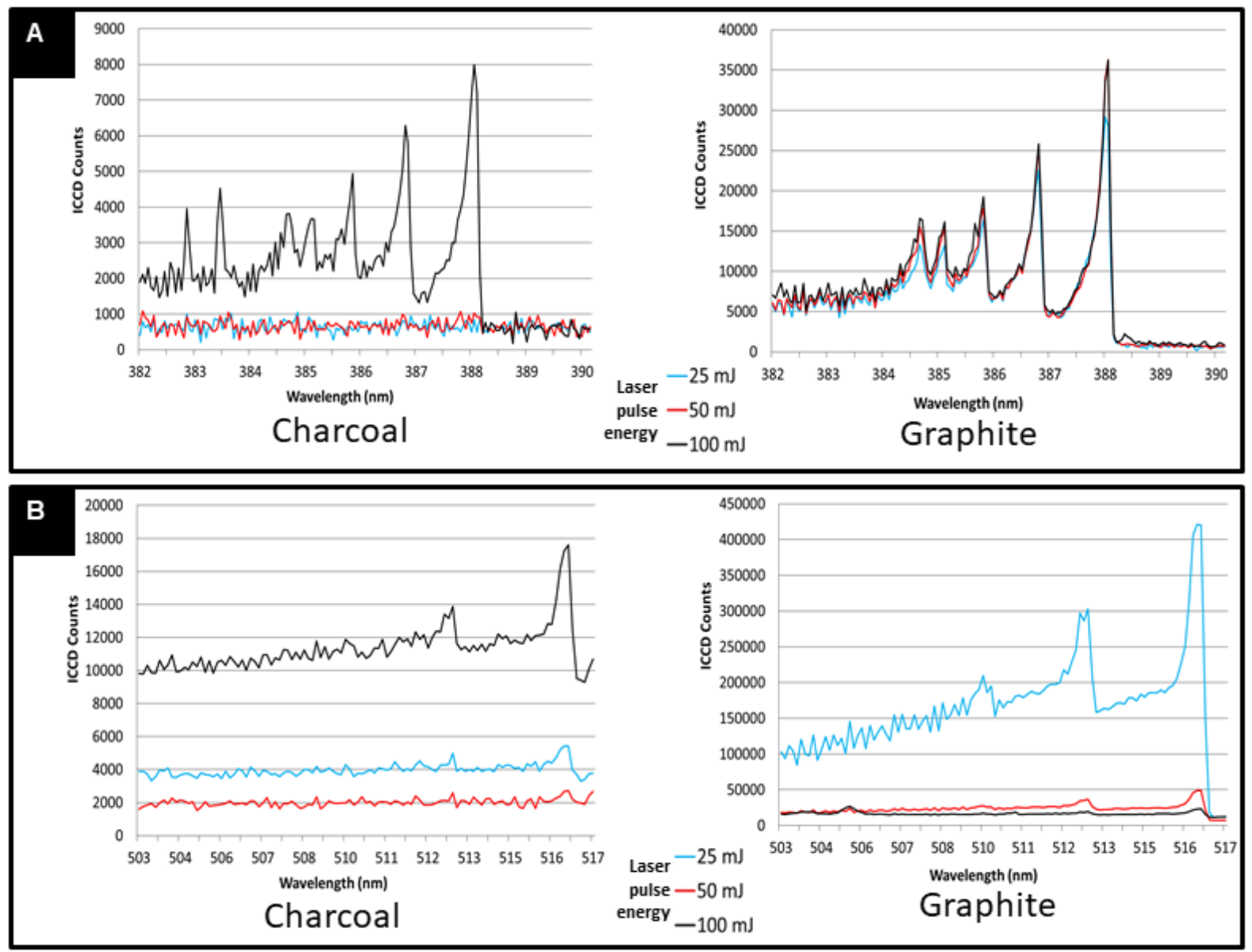

Figure 10

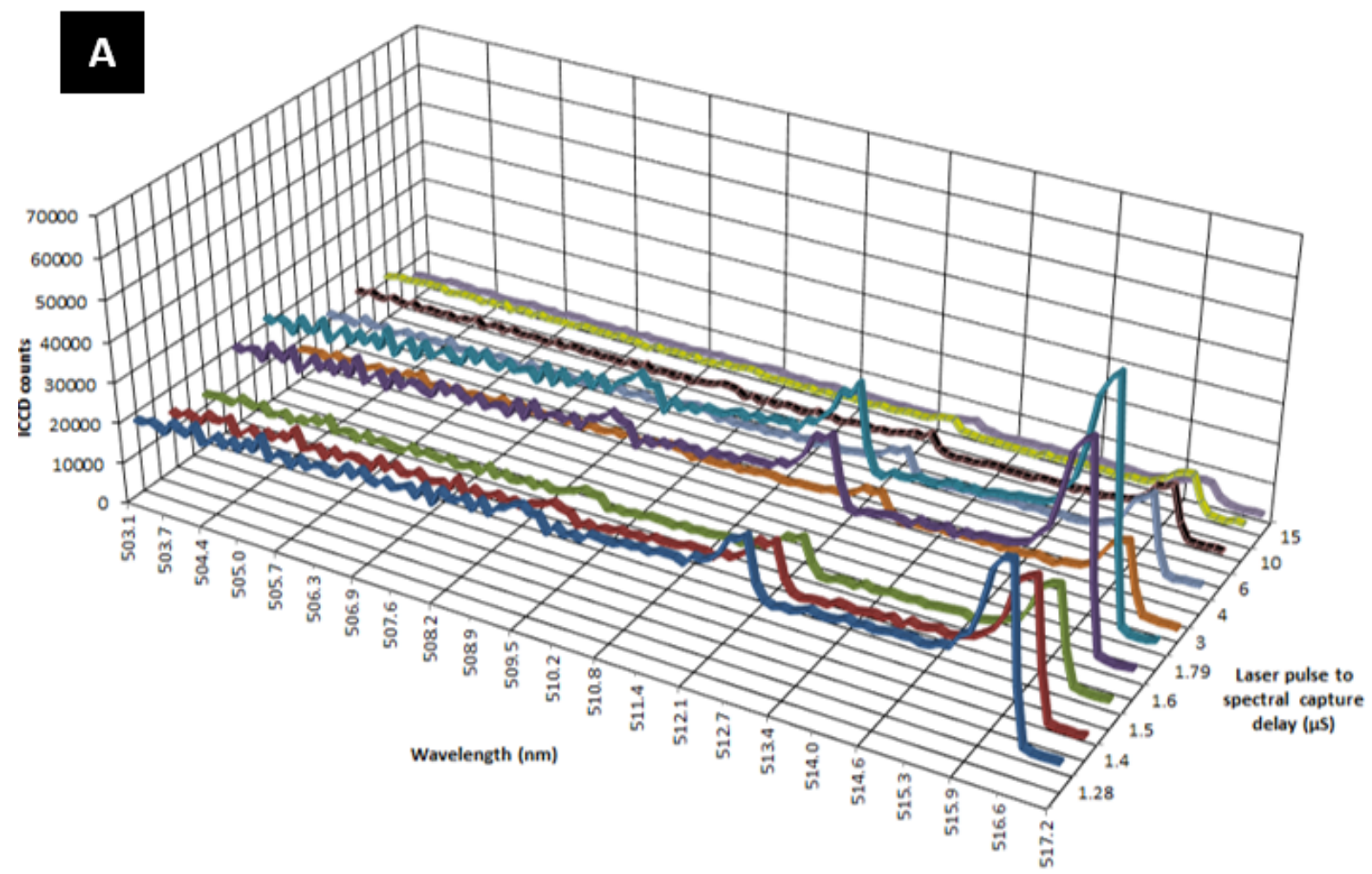




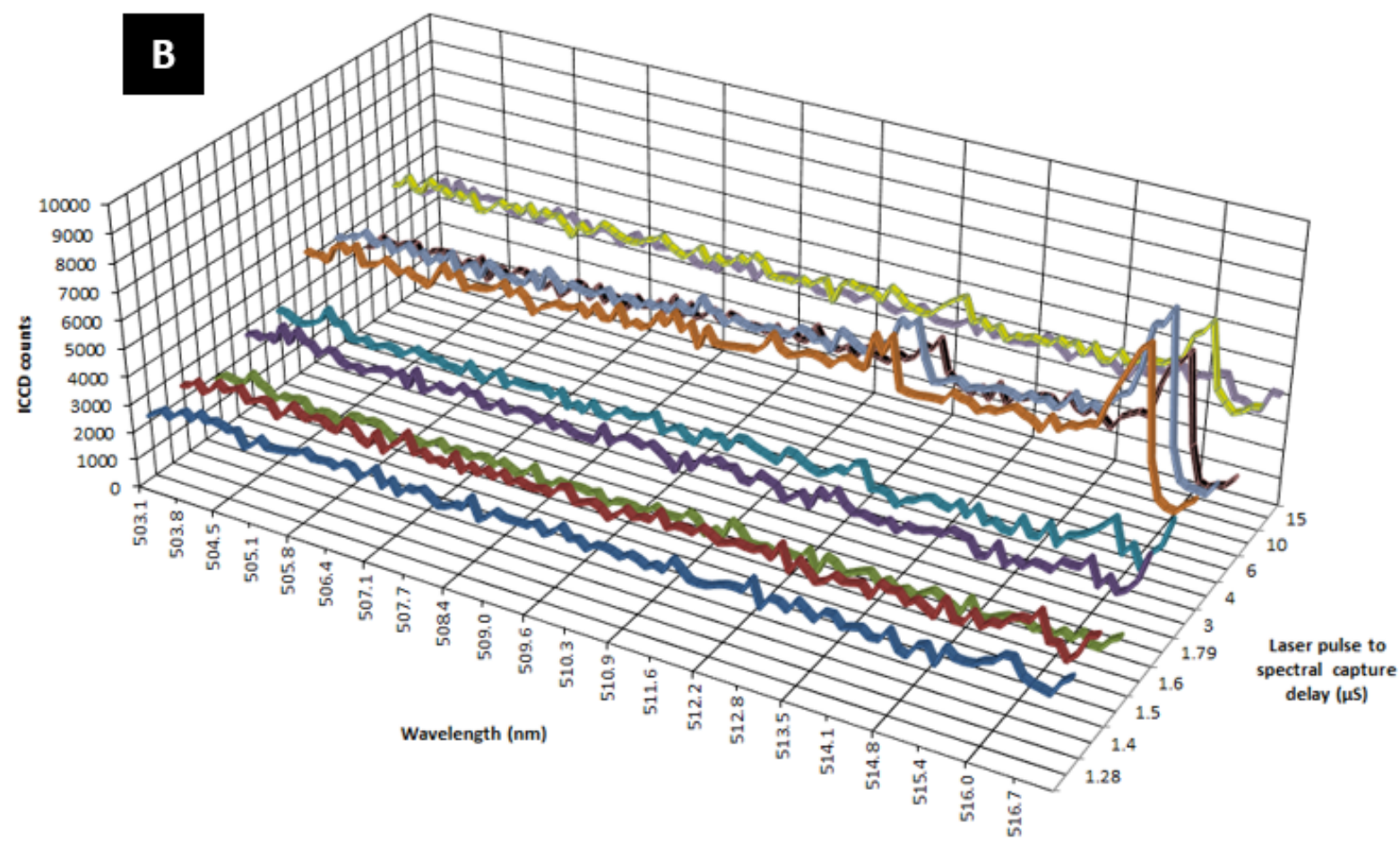

Figure 11

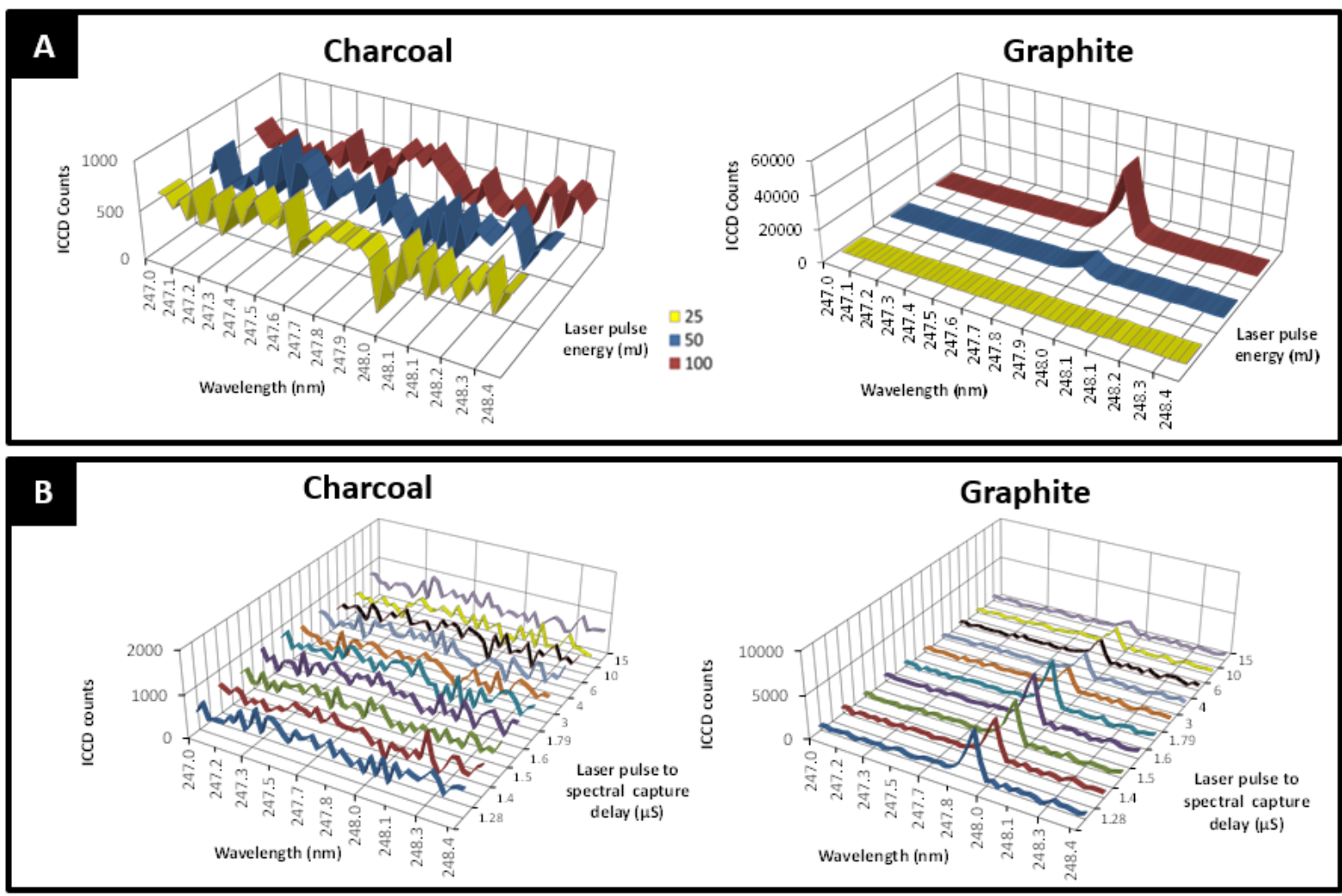

Figure 12 


$$
\begin{aligned}
& \hline \text { LIBS Experimental set up: } \\
& \text { : } 1.28 \text { As delay time } \\
& \text { : ns laser pulse duration } \\
& \text { - Up to at least } 50 \text { mJ laser pulse energy } \\
& \text { - In-situ possible } \\
& \text { - In air }
\end{aligned}
$$

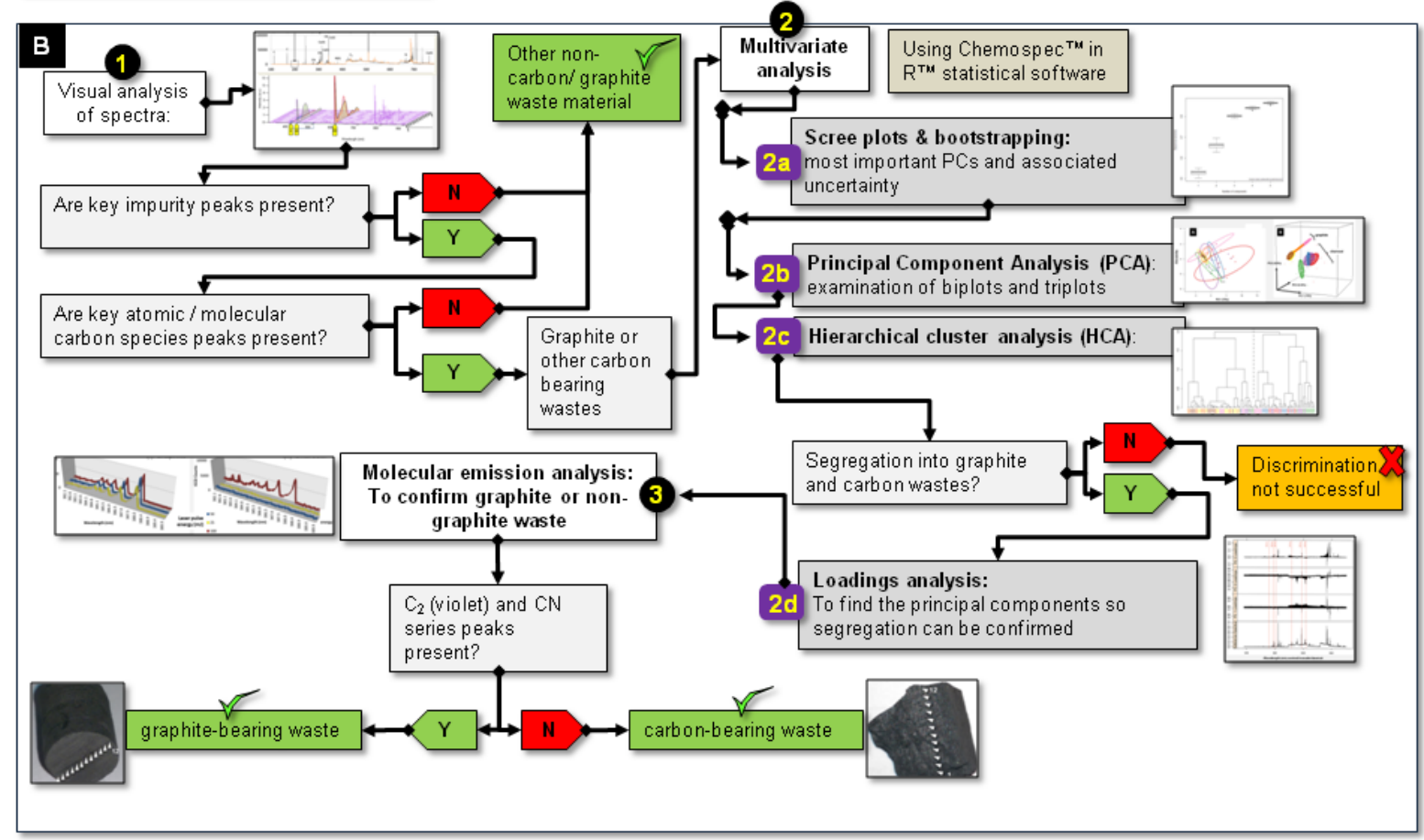


Table1

\begin{tabular}{|l|l|l|l|}
\hline Element & $\mathrm{ppm}$ & Element & $\mathrm{ppm}$ \\
\hline $\mathrm{S}$ & 50 & $\mathrm{Zn}$ & 0.13 \\
\hline $\mathrm{Si}$ & 35 & $\mathrm{~W}$ & 0.12 \\
\hline $\mathrm{Ca}$ & 35 & $\mathrm{~B}$ & 0.1 \\
\hline $\mathrm{V}$ & 12 & $\mathrm{Mg}$ & 0.1 \\
\hline $\mathrm{N}$ & 10 & $\mathrm{Mo}$ & 0.1 \\
\hline $\mathrm{Ti}$ & 3 & $\mathrm{Bi}$ & 0.08 \\
\hline $\mathrm{Cl}$ & 2 & $\mathrm{Li}$ & 0.05 \\
\hline $\mathrm{Ba}$ & 1.5 & $\mathrm{In}$ & 0.05 \\
\hline $\mathrm{Na}$ & 1 & $\mathrm{Sm}$ & 0.04 \\
\hline $\mathrm{Al}$ & 1 & $\mathrm{Cd}$ & 0.04 \\
\hline $\mathrm{Ni}$ & 1 & $\mathrm{Be}$ & 0.02 \\
\hline $\mathrm{Sr}$ & 0.4 & $\mathrm{Co}$ & 0.02 \\
\hline $\mathrm{Cr}$ & 0.35 & $\mathrm{Eu}$ & 0.005 \\
\hline $\mathrm{Pb}$ & 0.15 & $\mathrm{Ag}$ & 0.001 \\
\hline
\end{tabular}

Table 2

\begin{tabular}{|l|l|l|l|}
\hline Element & $\mathrm{ppm}$ & Element & $\mathrm{ppm}$ \\
\hline $\mathrm{C}$ & 951430 & $\mathrm{P}$ & 39 \\
\hline $\mathrm{Ca}$ & 21623 & $\mathrm{Fe}$ & 28 \\
\hline $\mathrm{K}$ & 9490 & $\mathrm{Te}$ & 27 \\
\hline $\mathrm{Mg}$ & 3197 & $\mathrm{Rb}$ & 8.3 \\
\hline $\mathrm{Si}$ & 312 & $\mathrm{Mn}$ & 7.9 \\
\hline $\mathrm{Sr}$ & 135 & $\mathrm{Hg}$ & 7.4 \\
\hline $\mathrm{Na}$ & 134 & $\mathrm{Sn}$ & 5.3 \\
\hline $\mathrm{S}$ & 76 & $\mathrm{Cs}$ & 4.3 \\
\hline $\mathrm{Al}$ & 64 & $\mathrm{U}$ & 3.5 \\
\hline
\end{tabular}

Table 3

\begin{tabular}{|c|c|c|c|c|c|}
\hline $\begin{array}{c}\text { Atom } \\
*\end{array}$ & $\begin{array}{c}\text { Transition } \\
\text { Upper to lower }\end{array}$ & $\begin{array}{c}\text { Wavelength } \\
(\mathbf{n m})\end{array}$ & Comment & $\begin{array}{c}\text { Visible in } \\
\text { graphite } \\
(\mathrm{Y}=\mathrm{yes} ; \mathrm{N}=\mathrm{no})\end{array}$ & $\begin{array}{c}\text { Visible in } \\
\text { charcoal } \\
\text { (Y=yes; } \mathrm{N}=\mathrm{no})\end{array}$ \\
\hline $\mathrm{C}(\mathrm{I})$ & $2 \mathrm{~s}^{2} 2 \mathrm{p} 3 \mathrm{~s}-2 \mathrm{~s}^{2} 2 \mathrm{p}^{2}$ & $\begin{array}{l}193.09 \mathrm{~nm} \\
\&\end{array}$ & & $\mathrm{Y}$ & $\mathrm{N}$ \\
\hline
\end{tabular}




\begin{tabular}{|c|c|c|c|c|c|}
\hline & & $247.86 \mathrm{~nm}$ & & & \\
\hline $\mathrm{C}_{2}$ & $d^{3} \Pi_{g}-a^{3} \Pi_{m}$ & $516 \mathrm{~nm}$ & $\begin{array}{l}\text { Head peak for } \\
\text { Swan series } \\
(0,0)\end{array}$ & $\mathrm{Y}$ & $\mathrm{Y}$ \\
\hline $\begin{array}{l}\mathrm{Ca}(\mathrm{II}) \\
\mathrm{Ca}(\mathrm{II}) \\
\mathrm{Ca}(\mathrm{I})\end{array}$ & $\begin{array}{l}3 p^{6} 4 s-3 p^{6} 4 p \\
3 p^{6} 4 s-3 p^{6} 4 p \\
3 p^{6} 4 s 4 p-3 p^{6} 4 s 2\end{array}$ & $\begin{array}{l}393.37 \mathrm{~nm}, \\
396.85 \mathrm{~nm}, \\
422.67 \mathrm{~nm}\end{array}$ & $\begin{array}{l}\text { Chamberlain } \\
\text { (2012) [54] }\end{array}$ & $\mathrm{Y}$ & $\mathrm{N}$ \\
\hline $\mathrm{CN}$ & B $2 \Sigma^{+}-\mathrm{X} 2 \Sigma^{+}$ & $\begin{array}{l}358.58 \mathrm{~nm} \\
\text { Head band } \\
388.25 \mathrm{~nm}\end{array}$ & $\begin{array}{l}\text { Line much more } \\
\text { dominant in } \\
\text { graphite. } \\
\mathrm{CN} \text { series clear } \\
\text { in both materials }\end{array}$ & $\mathrm{Y}$ & $\mathrm{Y}$ \\
\hline $\mathrm{Fe}(\mathrm{I})$ & $\begin{array}{l}3 d^{7}(4 F) 4 d- \\
3 d^{7}(4 F) 4 p \\
3 d^{6}(5 D) 4 s 4 p\left(3 P^{\circ}\right)- \\
3 d^{7}(4 F) 4 s\end{array}$ & $\begin{array}{l}610.22 \mathrm{~nm} \\
\& \\
610.32 \mathrm{~nm}, \\
612.03 \mathrm{~nm}\end{array}$ & $\begin{array}{l}\text { Unresolved } \\
\text { double peak }\end{array}$ & $\bar{Y}$ & $\mathrm{~N}$ - due to noise \\
\hline $\mathrm{Mg}(\mathrm{II})$ & $2 p^{6} 3 s-2 p^{6} 3 p$ & $\begin{array}{l}279.65 \mathrm{~nm}, \\
280.26 \mathrm{~nm}, \\
285.23 \mathrm{~nm}\end{array}$ & & $\mathrm{Y}$ & $\mathrm{N}$ - due to noise \\
\hline $\mathrm{Na}(\mathrm{I})$ & $2 p^{6} 3 p-2 p^{6} 3 s$ & $\begin{array}{l}588.99 \mathrm{~nm}, \\
589.59 \mathrm{~nm}\end{array}$ & & $\mathrm{Y}$ & $\mathrm{Y}$ \\
\hline
\end{tabular}

*Spectroscopic notation is that the neutral atom is labelled (I): subsequent oxidation by (II), etc.

Table 4

\begin{tabular}{|c|c|c|c|c|c|}
\hline Series & $\begin{array}{c}\text { Laser } \\
\text { pulse } \\
\text { energy } \\
(\mathrm{mJ})\end{array}$ & $\begin{array}{c}\text { Graphite } \\
\text { peaks }\end{array}$ & $\begin{array}{l}\text { Crushed } \\
\text { Compressed } \\
\text { Charcoal }\end{array}$ & Reason & $\begin{array}{l}\text { Discrimination } \\
\text { possible? }\end{array}$ \\
\hline \multirow{3}{*}{$\begin{array}{l}\text { CN (Violet) } \\
388.3 \mathrm{~nm}\end{array}$} & 25 & $\bar{Y}$ & $\mathrm{~N}$ & & $\mathrm{Y}$ \\
\hline & 50 & $\mathrm{Y}$ & $\mathrm{N}$ & & $\mathrm{Y}$ \\
\hline & 100 & $\mathrm{Y}$ & $\bar{Y}$ & $\begin{array}{c}\text { CN produced } \\
\text { by interaction } \\
\text { of either } \mathrm{C}_{2} \\
\text { clusters, or } \\
\text { atomic } \\
\text { carbon with } \\
\text { atmospheric } \\
\mathrm{N}\end{array}$ & $\begin{array}{l}\text { No - Not at this } \\
\text { laser pulse } \\
\text { energy }\end{array}$ \\
\hline \multirow[t]{2}{*}{$\begin{array}{l}\text { Swan series } \\
516 \mathrm{~nm}\end{array}$} & 25 & $\bar{Y}$ & $\begin{array}{c}\text { - but only } \\
\text { head at } \\
516 \mathrm{~nm}\end{array}$ & & $\mathrm{~N}$ \\
\hline & 50 & $\bar{Y}$ & $\mathrm{~N}$ & & $\bar{Y}$ \\
\hline
\end{tabular}




\begin{tabular}{|l|l|l|l|l|l|}
\hline & 100 & $\mathrm{Y}$ & $\mathrm{N}$ & & $\mathrm{Y}$ \\
\hline
\end{tabular}


The Editor

Journal of Environmental Radioactivity

Elsevier B.V.

Radarweg 29

1043 NX Amsterdam

The Netherlands

\section{$13 /$ Jun/2018}

Your Ref: Article title: "A new analysis workflow for discrimination of nuclear grade graphite using laserinduced breakdown spectroscopy"
National Nuclear Laboratory

5th Floor

Chadwick House

Warrington Road

Birchwood Park

Warrington

WA3 $6 \mathrm{AE}$
T. $+44(0) 1925289800$
E. customers@nnl.co.uk
W. www.nnl.co.uk

\section{Article submission to the Journal of Environmental Radioactivity}

\section{Dear Editor .,}

We would be grateful if you would consider our manuscript entitled "A new analysis workflow for discrimination of nuclear grade graphite using laser-induced breakdown spectroscopy" for publication within the Journal of Environmental Radioactivity.

Over 250,000 tons of various nuclear-grade graphite, and graphite-bearing, materials exist throughout the world, and are a major issue for nuclear decommissioning and radioactive waste management, due to the long half-lives of the associated ${ }^{14} \mathrm{C}$ and ${ }^{36} \mathrm{Cl}$ isotopes.

Characterisation of such waste materials is a critical activity in understanding the nature of the waste, ensuring hazardous material is managed safely and that waste can be segregated for reuse, recycle, or sentenced for appropriate disposal. However, characterisation of materials, often in hostile environments, is ideally undertaken in-situ to differentiate between materials in terms of their chemical composition and radioactivity.

This paper describes the successful use of LIBS analysis for the discrimination of preirradiated nuclear 'Pile Grade A' (PGA) graphite moderator rod and domestic lumpwood charcoal, which act as surrogates for nuclear grade graphite and other carbon-bearing wastes respectively. Within the paper we propose a new analysis workflow utilising LIBS. Subsequent examination of spectral characteristics, multivariate analysis, and molecular isotopic spectroscopy is proposed to enable rapid segregation of graphite from a heterogeneous waste stream. Enhanced characterisation techniques, such as those described in this paper, have the potential to significantly reduce the cost of decommissioning large parts of legacy nuclear generation plants. 
This paper marks the first time LIBS has been used as a fingerprinting and discriminatory tool for the characterisation of graphite and heterogeneous carbonaceous wastes. Particular highlights we present include:

- A new approach to graphite waste segregation, using LIBS, in nuclear decommissioning,

- How multivariate analysis of LIBS spectra enables identification of graphite,

- How LIBS molecular emission fingerprinting is key to graphite identification,

- Laser pulse (ns) energies of greater than $90 \mathrm{~mJ}$ are experimentally determined as being unsuitable for analysis,

- A LIBS analysis workflow for nuclear grade graphite identification is proposed.

The word count for this paper is 6663 .

Thank you for your consideration.

Yours sincerely

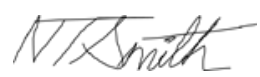

Prof Nick Smith (corresponding author)

E. nick.t.smith@nnl.co.uk

T. 01925289899 
Article submission to the Journal of Environmental Radioactivity: "A new analysis workflow approach for discrimination of nuclear grade graphite using laser-induced breakdown spectroscopy"

Dear Gabi,

Thank you for your help so far with our research paper submission. We have responded to all reviewers' comments and have compiled them into a supporting document to help them review our responses.

We would like to say thank you to the reviewers for their time and effort, this is very much appreciated and helped make for a better article.

We would be grateful if you would consider our revised manuscript for publication.

Best wishes

Owen Horsfall 